\title{
Drainage area characterization for evaluating green infrastructure using the Storm Water Management Model
}

\author{
Joong Gwang Lee ${ }^{1}$, Christopher T. Nietch ${ }^{2}$, and Srinivas Panguluri ${ }^{3}$ \\ ${ }^{1}$ Center for Urban Green Infrastructure Engineering (CUGIE Inc), Cincinnati, OH 45255, USA \\ ${ }^{2}$ Office of Research and Development, US Environmental Protection Agency, Cincinnati, OH 45268, USA \\ ${ }^{3}$ Independent Consultant, Olney, MD 20832, USA
}

Correspondence: Joong Gwang Lee (jglee@ugiengineering.com)

Received: 21 March 2017 - Discussion started: 19 May 2017

Revised: 22 March 2018 - Accepted: 3 April 2018 - Published: 3 May 2018

\begin{abstract}
Urban stormwater runoff quantity and quality are strongly dependent upon catchment properties. Models are used to simulate the runoff characteristics, but the output from a stormwater management model is dependent on how the catchment area is subdivided and represented as spatial elements. For green infrastructure modeling, we suggest a discretization method that distinguishes directly connected impervious area (DCIA) from the total impervious area (TIA). Pervious buffers, which receive runoff from upgradient impervious areas should also be identified as a separate subset of the entire pervious area (PA). This separation provides an improved model representation of the runoff process. With these criteria in mind, an approach to spatial discretization for projects using the US Environmental Protection Agency's Storm Water Management Model (SWMM) is demonstrated for the Shayler Crossing watershed (SHC), a well-monitored, residential suburban area occupying 100 ha, east of Cincinnati, Ohio. The model relies on a highly resolved spatial database of urban land cover, stormwater drainage features, and topography. To verify the spatial discretization approach, a hypothetical analysis was conducted. Six different representations of a common urbanscape that discharges runoff to a single storm inlet were evaluated with eight $24 \mathrm{~h}$ synthetic storms. This analysis allowed us to select a discretization scheme that balances complexity in model setup with presumed accuracy of the output with respect to the most complex discretization option considered. The balanced approach delineates directly and indirectly connected impervious areas (ICIA), buffering pervious area (BPA) receiving impervious runoff, and the other pervious area within a SWMM subcatchment. It performed
\end{abstract}

well at the watershed scale with minimal calibration effort (Nash-Sutcliffe coefficient $=0.852 ; R^{2}=0.871$ ). The approach accommodates the distribution of runoff contributions from different spatial components and flow pathways that would impact green infrastructure performance. A developed SWMM model using the discretization approach is calibrated by adjusting parameters per land cover component, instead of per subcatchment and, therefore, can be applied to relatively large watersheds if the land cover components are relatively homogeneous and/or categorized appropriately in the GIS that supports the model parameterization. Finally, with a few model adjustments, we show how the simulated stream hydrograph can be separated into the relative contributions from different land cover types and subsurface sources, adding insight to the potential effectiveness of planned green infrastructure scenarios at the watershed scale.

\section{Introduction}

Conventional stormwater modeling has focused on the design of urban drainage systems and flood control practices that achieve fast drainage and reduce risk of flooding (NRC, 2009; WEF-ASCE, 2012). These objectives focus attention on larger storms, such as 2- to 10-year return period storms for designing drainage systems and 25- to 100-year storms for designing flood control practices (WEF-ASCE, 2012). Conversely, nearly $95 \%$ of pollutant runoff from urban areas is produced from events smaller than a 2-year storm (Guo and Urbonas, 1996; Pitt, 1999; NRC, 2009). It is well recognized that the best way to resolve this pollution problem is to 
implement controls as close to the source of runoff generation as possible (Debo and Reese, 2002; WEF-ASCE, 2012).

Green infrastructure (GI) practices were developed to correct this water pollution problem and restore the natural hydrologic cycle (WEF-ASCE, 2012; USEPA, 2014). GI includes structures like green roofs, rain barrels, bioretention areas, buffer strips, vegetated swales, permeable pavements, and infiltration trenches, or practices, such as disconnecting downspouts. The specific design objectives for GI include minimizing the impervious areas directly connected to the storm sewer, increasing surface flow path lengths or time of concentration, and maximizing on-site depression storage and infiltration at the lot level (WEF-ASCE, 2012). This translates operationally to individual stormwater management practices that are relatively small but densely distributed in space (USEPA, 2009). Although GI is distributed at higher spatial densities, each unit is relatively inexpensive if the unit can be considered as part of landscaping and, in total, may provide a cost-effective alternative to more traditional larger centralized practices, like detention ponds especially in cases where land is not available or very expensive.

There is a great deal of interest in modeling GI effects at watershed scales to help inform regional stormwater management planning and design decisions. However, from a stormwater modeling perspective, the approach taken for model representations of GI requires different methodological considerations compared to the traditional large-size, low spatial density of the more centralized and regional control features (Fletcher et al., 2013; USEPA, 2012; Guo, 2008). While conventional stormwater management practices have focused on end-of-pipe controls at the downstream end of the drainage area (i.e., centralized systems), GI practices focus on on-site controls at the upstream side (i.e., distributed systems). The surface hydrologic properties (e.g., land cover, slope, overland flow path) remain the same before or after applying centralized systems, but they are altered with on-site GI systems. GI practices aim to amend the landscape hydrologic properties to reduce the negative impacts of stormwater (USEPA, 2007). Hence, modeling approaches for evaluating GI should be able to account for the changing surface hydrologic properties that come with GI implementation.

The Storm Water Management Model (SWMM) of the United States Environmental Protection Agency (USEPA) is one tool that has a large user base and a broad application history for informing stormwater management projects around the world (Niazi et al., 2017). In the current version of the model, GI effects are simulated using low-impact development (LID) algorithms. LID is largely synonymous with GI in SWMM vernacular. The LID modeling options were added in 2010 (Rossman, 2015; Rossman and Huber, 2016). Since then, while numerous LID/GI modeling studies have been introduced, best modeling practices for simulating GI in SWMM have received comparatively little attention in the literature (Niazi et al., 2017).
This study was intent on evaluating approaches to modeling GI effects at a watershed scale using SWMM. In the setup of a SWMM model, the urban area of interest is divided into smaller spatial units, referred to as subcatchments. To implement a traditional stormwater control feature like a retention pond, it is usually acceptable to provide minimal detail of the drainage area (Rossman and Huber, 2016). This leads to spatial aggregation which tends to produce larger subcatchment areas that aggregate land cover types and simplify the existing storm sewer system to realize a more cost-effective model setup and output data management. If the simulated hydrographs are matched with the observed data during model calibration, the model is considered a sound representation of the drainage processes important for designing the retention pond. The trade-off is that coarser schematization requires more decisions on how to aggregate catchment properties (Rossman and Huber, 2016). In contrast, for simulation of GI, the construction reality is that GI is built as part of building and landscape arrangements all upgradient of the drainage network (Dietz, 2007; Montalto et al., 2007; USEPA, 2009; Zhou, 2014). Therefore, to accurately examine GI alternatives, a drainage area for modeling should be defined as an area that drains runoff to a storm sewer inlet with no or minimal spatial aggregation of landscape features affecting hydrologic properties. In SWMM, this drainage area is modeled as single or multiple subcatchments. Since SWMM version $4.4 \mathrm{H}$, overland flow routing is allowed from one subcatchment to another (Huber, 2001; Huber and Cannon, 2002). To minimize confusion between real and modeled drainage areas, we coin the term hydrologic response element (HRE) in this study. An HRE is the drainage area (i.e., a real spatial element of the landscape being modeled) where GI practices may be implemented to control the element's surface runoff prior to discharge to the stormwater collection system. There are many alternatives for configuring the HRE for GI modeling in SWMM. We evaluate six different options in this study.

In SWMM, the subcatchment representation of the HRE is comprised of one or more homogeneous subareas, such as impervious or pervious area, impervious area (IA) with or without depression storage, directly connected impervious area (DCIA) or indirectly connected impervious area (ICIA), or LID area (Rossman, 2015; Rossman and Huber, 2016). In urban landscapes, DCIA discharges runoff to the existing storm sewer system without any control, while ICIA discharges to the adjacent pervious area (PA). The PA that receives runoff from ICIA works like a buffer strip or swale, therefore acting like an existing GI practice, albeit not intentionally designed as such. This is a real characteristic of urban areas that is termed buffering pervious area (BPA) in this study. The other pervious area is called standalone pervious area (SPA) that does not receive or control any runoff from impervious area. An HRE may consist of all or part of these subareas - DCIA, ICIA, BPA, and SPA - and implementing GI practices can change subarea ratios and proper- 
ties, surface runoff processes, and flow pathways within the HRE. Each subarea may also consist of different land cover components. For example, DCIA may include paved streets, building rooftops, driveways, or sidewalks. In this study, we questioned how these spatial and hydrologic realities should be modeled using SWMM.

After the HRE delineation is performed in SWMM, each HRE undergoes a model parameterization procedure that defines the relative proportions of impervious and pervious subareas, how they interact in terms of surface flow pathways, and their hydrologic properties (Rossman, 2015). The subcatchment/subarea configuration of each HRE ultimately specifies the physical conditions used by the model's mathematical algorithms to simulate the dynamics of hydrologic loading to the drainage network. The more subcatchments there are, the more input and output values there are to be managed by the modeler. When setting up a SWMM model using the conventional objectives, such as deriving hydrographs for designing storm collection systems and/or detention-retention systems, the subcatchment parameterization remains the same before and after simulation of the management practice; however, for GI simulation, the internal properties of a subcatchment change, as mentioned earlier. Pending the type of GI, changes may need to be made to the hydrologic properties of subareas or individual land cover components, the proportions of impervious and pervious area, the specification for the routing of runoff between them, the flow path length, and infiltration or the depression storage properties. Adequately rationalizing and tracking these changes can become a problem for the modeler when the total area being modeled is relatively large and aggregated, the GI scenarios are not the same among HREs, or the internal properties among HREs are heterogeneous. A systematic approach to characterizing HREs would help make SWMM GI simulation projects more efficient.

The question of how to best parameterize SWMM is not new, especially when it comes to spatial resolution and scaling, but as mentioned, GI modeling, in particular, requires special considerations. This paper describes a suggested method for modeling GI in SWMM and provides critical evaluation. Primary objectives of this study are to (1) examine how to configure HREs for GI modeling and (2) develop a methodology for parameterizing a SWMM model that reflects this configuration with the goal of demonstrating an urban watershed spatial discretization approach that optimizes model performance in terms of tracking model input values and presumed accuracy of the results. We hypothesized that conventional modeling approaches to subcatchment delineation are likely aggregating at too-coarse resolution in space and hydrologic response to be appropriate for highly spatially distributed modern GI. We also questioned how the SWMM setup could not only allow for modeling the effects of various GI scenarios, but also facilitate the scaling of GI scenarios from a small HRE, representing the parcel or lot level, to a watershed level. To answer these ques- tions, we examine several acceptable approaches to representing spatial reality in SWMM when the modeling objective is to inform decisions about GI implementation. We use a hypothetical HRE-based analysis of spatial discretization alternatives to test our hypothesis related to the appropriateness of spatial and hydrologic response resolution. The hypothetical HRE represents a typical residential area that drains to a storm sewer inlet. The hypothetical HRE is modeled in SWMM by combining six conceivable options in spatial representation and eight design storms that represent the full spectrum of runoff events. From this analysis, an appropriate option is selected for GI modeling in SWMM, and a baseline SWMM model is developed using it for representing the existing condition of a well-characterized 100 ha urban watershed in a headwater area east of Cincinnati, Ohio. To examine the proposed approach, another SWMM model is developed for simulating a GI implementation scenario at the study watershed. Also, an approach for hydrograph separation is presented using the developed SWMM models, which can provide insight for arranging GI implementation scenarios. Currently, there is no provision for accomplishing this in SWMM.

\section{Materials and methods}

\subsection{Study area}

An experimental urban watershed drained by a natural headwater stream that does not have any surface stormwater inflows from outside its topographic boundaries was used for this study (Fig. 1). The Shayler Crossing watershed (SHC) is located east of Cincinnati, Ohio, and occupies approximately 100 ha that is characterized as $62.6 \%$ urban or developed, $25.6 \%$ agriculture, and $11.8 \%$ forested based on the 2011 National Land Cover Database (Homer et al., 2015). The native soils of the watershed are characterized with high silty clay loam content and therefore are naturally poorly infiltrating.

\subsection{The baseline spatial database}

\subsubsection{Data from the county GIS}

Spatial data for the study area was provided by the Clermont County Office of Environmental Quality, which included a detailed GIS of the existing stormwater drainage system and surface topography. The drainage system consists of storm sewer inlets (or catch basins), manholes, pipes, wet-dry detention ponds, and channel network. The county GIS contains the location of the drainage system, invert elevations for inlets and manholes, and pipe sizes. Two types of surface topography data were also available; $0.76 \mathrm{~m}$ (2.5 feet) lidar (light detection and ranging) data and $0.3 \mathrm{~m}$ contours. High-resolution aerial orthophotographs were also provided by the county. Existing databases that include the details for 

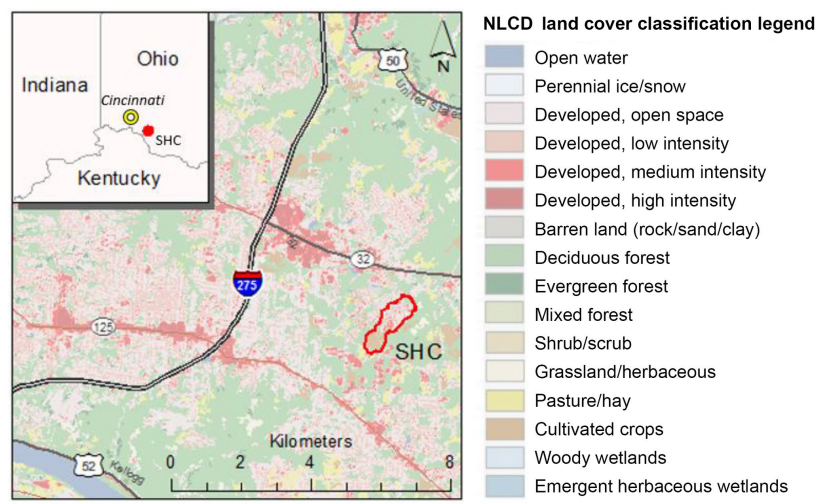

Figure 1. Location of the Shayler Crossing watershed. I-275 is an interstate highway around the Cincinnati metropolitan area.

the stormwater infrastructure like in this watershed are not always available to the modeler. In these cases, to adopt the subsequently described approach to GI scenario modeling in SWMM could require considerable ground-truthing and site surveying. In lieu of on-site visits, and as will become apparent from the descriptions below, what would be most important is determining the spatial location of storm sewer inlets. These are often visible from readily available aerial photographs; note that the visibility depends on the underlying image quality and the presence of obstacles such as trees or cars. When elevation data for the storm sewer network is unavailable, much can be inferred using surface elevation data and assuming local construction codes for stormwater infrastructures were applied, such as catch basin depths and conveyance pipe diameters and slopes. Such approximations would suffice for GI scenario analysis considerations and where storm sewer design is not the primary focus.

\subsubsection{Detailed land cover and subarea categorization}

To obtain a high-resolution digital characterization of spatial reality in the study watershed, 16 unique land cover types were identified and digitized using ArcGIS 10.2 (ESRI, 2013) spatial analysis tools on the aerial orthophotographs of the study area. These 16 types are later aggregated to 10 for setting up the watershed SWMM model (see Appendix). The resulting baseline spatial database included individual records of the watershed surface that could be used to access the location, pattern, and extent of the following sixteen land cover types: streets, parking areas, sidewalks, driveways, main buildings, miscellaneous buildings, paved walking paths, patios, other miscellaneous impervious areas, landscaped or lawn areas, agriculture, forest, dry ponds, stormwater detention area (in SHC this is created by the addition of a control structure to the stream channel itself), swimming pools, and wet ponds. Each spatial record has its own attributes (i.e., fields in the database) representing the current conditions (e.g., area, land cover) and was characterized based on its future potential for GI implementation (e.g., to evaluate the potential of downspout disconnection for a main building). The initial parameterization and GI modeling approaches described below for the SWMM model are based on content extracted from this land cover database created using ArcGIS tools. This database is often reused to perform model adjustments during calibration and GI scenario analysis. The developed land cover database for SHC contains a total of 3682 records and the median area of each record is $23.5 \mathrm{~m}^{2}$.

Each surface record in the database is further classified into four types based on its hydrologic characteristics including (1) DCIA, (2) ICIA, (3) pervious area (PA), or (4) water. The PA is subsequently split into two subcategories called BPA and SPA after the HRE delineation procedure for SWMM modeling is completed (see below). All main buildings are DCIA because the rooftop downspouts in the existing condition are plumbed to directly discharge to the stormwater collection system through buried pipes or street gutters. All the miscellaneous buildings (e.g., storage sheds) are considered ICIA. Streets with curb-and-gutter drainage systems are identified as DCIA. Any directly connected upgradient impervious areas to these streets are initially considered as DCIA. These areas include directly connected driveways, parking areas, and sidewalks. However, if both sides of a sidewalk are surrounded by a pervious area, the sidewalk is categorized as ICIA. Streets without curb-and-gutter drainage are ICIA. The remaining miscellaneous impervious areas are ICIA.

Figure 2 contains a sample GIS representation of the 16 land cover types along with a corresponding attribute table, which indicates hydrologic characteristics representing the baseline classification and a GI scenario-related classification. In the attribute table shown in Fig. 2, the first column contains the record identifier, the second column defines the land cover type, the third column defines how it was classified for modeling the baseline condition, the fourth column defines how it was classified or reclassified for modeling a specific GI scenario, and the fifth column specifies the contributing area. For example, the record ID 36 contained in the table is initially classified as DCIA, but, after the rooftop drains were disconnected in the modeled GI scenario, the unit was reclassified as ICIA (in the fourth column). This methodology allows for GI-related hydrology evaluation to be performed without impacting the overall SWMM model structure and setup. A companion USEPA report (Lee et al., 2017) has been prepared to provide the relevant details on the applied spatial analysis techniques such as clip, intersect, union, buffer, and manipulating attribute data.

\subsubsection{Configuring the BPA and SPA}

BPA is not considered explicitly in a traditional urban stormwater modeling analysis using SWMM. Instead the modeler usually sets up PA within a subcatchment to re- 


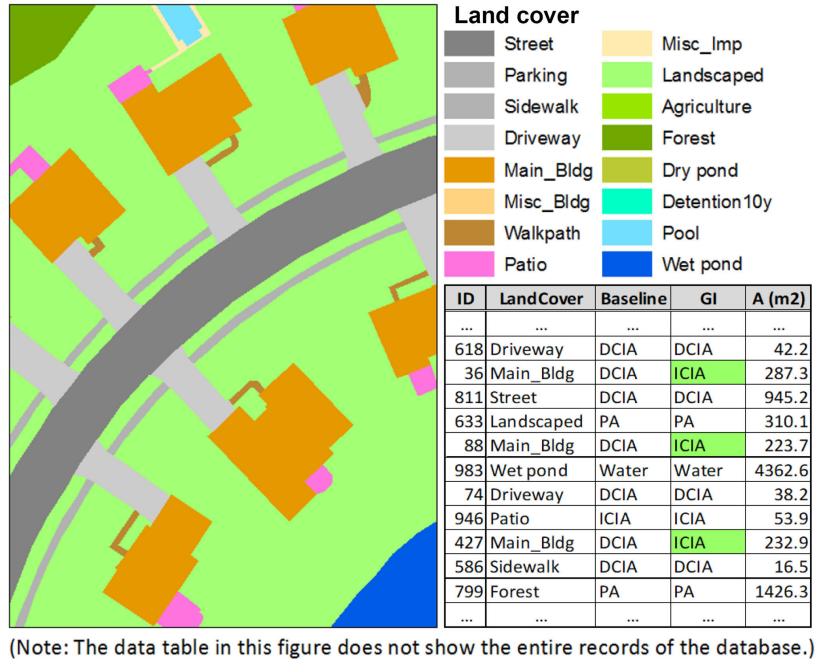

Figure 2. Sample GIS classified representation of the land cover and hydrologic characteristics.

ceive a certain percentage of runoff from impervious areas; this is how ICIA is distinguished from DCIA. However, in reality, not all of the PA receives runoff from ICIA, rather just the part of the PA that is immediately adjacent to the ICIA. When evaluating GI scenarios, one strategy might be to enlarge the size of the buffering area adjacent to ICIA, or engineer GI structures (e.g., cascading filtering or bioretention systems) around this buffering area (a.k.a. BPA) to reduce the direct runoff from impervious surfaces by routing them over grassy areas to slow down runoff and promote soil infiltration. Draining paved areas onto porous areas can reduce runoff volumes, rates, pollutants, and cost for drainage infrastructure (NRC, 2009; WEF-ASCE, 2012). Therefore, because of the nuanced, yet important differences, in the geospatial relationship of PA in different GI scenarios, we rationalized the need for retaining the ability to model this aspect while evaluating GI scenarios by splitting the PA into BPA and SPA for GI modeling in SWMM.

Characterizing the precise "physical" extent of BPA is a complicated process that would have to be defined from highly resolved surface topography around ICIA and an understanding of the unsaturated zone processes such as how infiltration and depression storage interact across the pervious surface types to influence flow path length. The physical extent of BPA is also affected by storm intensity, with higher intensity storms creating a larger spread of water across the surface and thereby increasing the extent of available adjacent buffering areas. Lacking the ability to infer flow path length without extensive physical measurements, we instead treat the width of the BPA from ICIA as a calibration parameter. In preparation for this, BPA based on different buffer widths was established during the development of the spatial database. This was done in ArcGIS using the geoprocessing tools "Buffer" and "Intersect". The Buffer tool established a

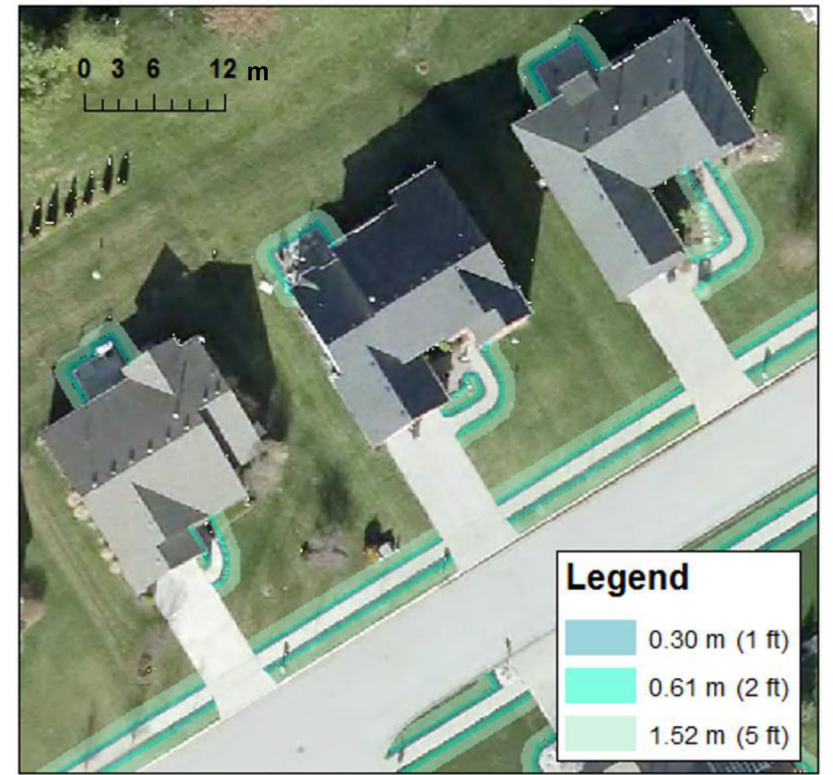

Figure 3. Depiction of the different distances applied for the estimation of BPA in the baseline condition using ArcGIS.

separate BPA area around all existing ICIA based on arbitrarily chosen distances that serve as equivalent buffer widths of $0.30,0.61$, and $1.52 \mathrm{~m}$ (Fig. 3). The Intersect tool establishes the area for the BPA and adjusts the area of the original pervious area from which it was subtracted, which is now SPA (Lee et al., 2017). Using this spatial information, we arranged three SWMM models that represent three different sizes of BPA. We determined which one among the three cases of BPA sizes provided the more accurate simulation compared to the observed flow data and as part of model calibration. In this way the BPA width was treated as a calibration parameter in this study.

\subsection{HRE delineation}

Urban HREs were delineated manually within the GIS using the surface topography $(0.76 \mathrm{~m}$ lidar $)$ and the layout of the storm sewer system (Rossman and Huber, 2016). Because GI is designed to capture and control stormwater runoff before it discharges to the storm sewer system, the HRE for GI analysis should be delineated as the area that drains runoff to an actual storm sewer inlet. With GI implementation, some inlets can be removed or combined for economic benefits because the peak and volume of stormwater discharge will be decreased after implementing GI practices (Sample et al., 2003; Braden and Johnston, 2004; USEPA, 2012). Based on this, two HREs are combined into one HRE if the two HREs were located side-by-side at one street location and one of the two HREs was smaller than $2023.4 \mathrm{~m}^{2}$ ( 0.5 acre). For undeveloped or agricultural areas in the study watershed, the HRE boundaries were generally selected with an intent to keep all 


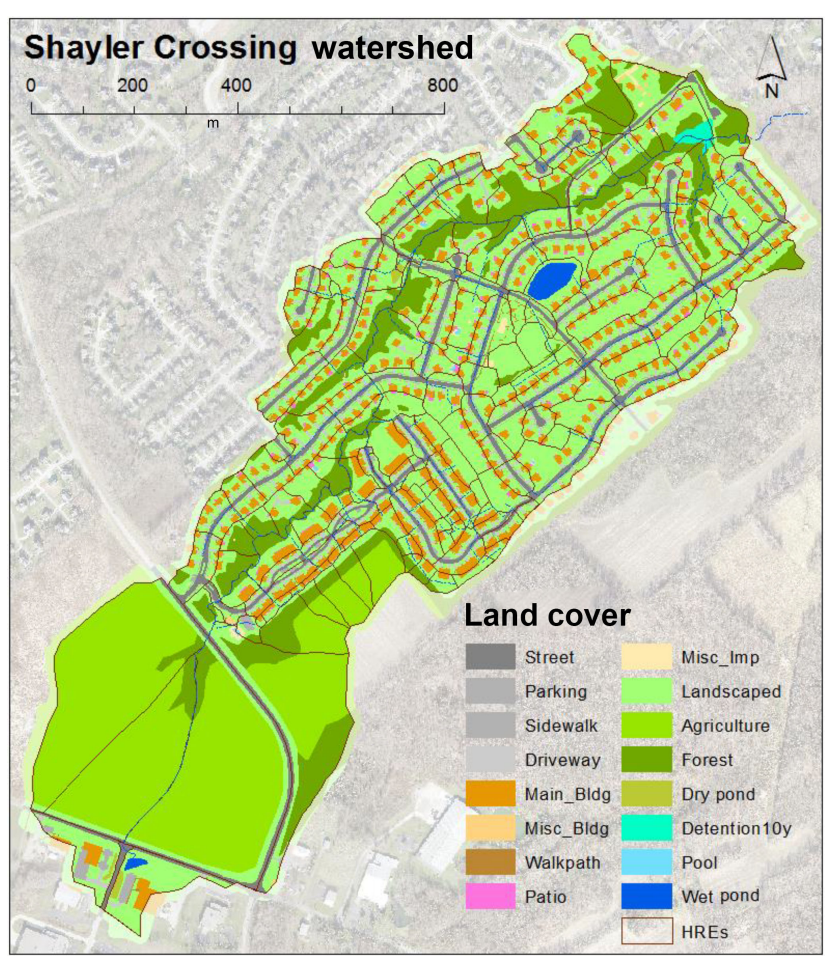

Figure 4. Detailed spatial representation of the Shayler Crossing watershed.

HREs a similar size to help maintain hydrologic continuity among them. The result of the HRE delineation for the entire SHC watershed is shown in Fig. 4.

\subsection{SWMM parameterization}

SWMM, developed by the USEPA, is a comprehensive mathematical model for analyzing hydraulics, hydrology, and water quality process dynamics in the urban environment (Huber and Dickinson, 1988; Gironás et al., 2009; Rossman, 2015; Rossman and Huber, 2016, Niazi et al., 2017). Here version 5.1.007 of SWMM was used. SWMM generates runoff when rainfall depth exceeds surface depression storage and infiltration capacity at the subcatchment scale. SWMM has extensive routing capability that can simulate the runoff through a conveyance system of pipes, channels, storage and treatment devices, pumps, and regulators. SWMM can also estimate the quality of runoff discharging from subcatchments and route it through the conveyance system. The model can be used within a continuous or event-based framework.

Unique to our application of the SWMM model is the setup of the BPA. This process is described in detail in the Appendix. Because the natural stream draining the study area receives lateral inflow through subsurface soil media (a.k.a. subsurface flow), SWMM's groundwater modeling options were implemented. The groundwater component of the SHC SWMM setup is also described in the Appendix.
A subcatchment is a fundamental hydrologic component of a SWMM application and can be defined as an area that drains runoff to a storm sewer inlet, open channel, or another subcatchment. The SWMM subcatchments in this study will represent the HREs that were delineated during the development of the spatial database described above. Each SWMM subcatchment is configured with a specific drainage area, \% imperviousness, width, and slope. Subareas divide each subcatchment into impervious, pervious, and/or LID areas that are used to account for internal heterogeneity. These areas are modeled in the abstract based on the relative percentage of the subcatchment each occupies; i.e., subareas have no real spatial reference. Therefore, all pervious areas within one subcatchment, for example, are lumped and modeled as one contributing hydrologic entity no matter how disconnected or patchy the actual physical reality may be. This establishes a relationship between the subcatchment size and the spatial resolution of the model. The larger the subcatchment area, especially in the urban environment, the more spatial lumping that results, and the more abstracted from reality the model becomes. The size of the subcatchment and the heterogeneity among land covers and their organization within each subcatchment or subareas interact to effect model complexity as well as accuracy. In most cases, modelers try to strike a balance between these when configuring a SWMM project. Subareas are parameterized by setting values characteristic of each, such as $n$ and DS for both IA and PA. The GreenAmpt option for infiltration modeling was used in this study, and this requires three parameters per subcatchment's PA, including the saturated hydraulic conductivity $\left(K_{\text {sat }}\right)$, capillary suction head (Suct), and initial soil moisture deficit (IMD). Internal flow between the subareas can be routed from pervious to impervious, impervious to pervious, or directly to the outlet. LID areas have their own set of parameters.

The spatial database that included land cover digitization and HRE delineations was used to parameterize the SWMM model. With the land cover data spatially overlaid with the HRE delineation in ArcGIS (Fig. 4), the characteristics of each SWMM subcatchment could be defined using the detailed land cover status per subcatchment and unique hydrologic parameters per land cover component presented in Table 1. Each land cover type is either all impervious or all pervious. "Length" represents a typical distance for overland flow before it turns into a concentrated flow path, which is controlled by the hydrologic design features of the land cover type. For example, overland flow at a rooftop is maintained only from the roof crest to the gutter because flow through a gutter is considered concentrated. The same regime change in flow (i.e., from overland flow to concentrated flow) may happen at any place where more than one instance of impervious land cover converge hydrologically, e.g., at a street gutter where overland flows from streets and driveways intersect. Using ArcGIS, the initial values for length were determined by averaging multiple field measurements of perceived overland flow lengths for each land cover type. More- 
detailed procedures for the SWMM modeling methods used in this study are presented in the Appendix.

\subsection{Model setup options for a hypothetical HRE in SWMM}

As mentioned earlier, an HRE can be modeled as a single subcatchment or multiple subcatchments in SWMM. In the SWMM model setup just described we used a single subcatchment setup that was based on the results of an analysis done with the goal of determining which among a series of plausible HRE configuration options strikes a balance among the degree of spatial and hydrologic aggregation, output uncertainty, and computational effort. The most spatially refined approach to a SWMM setup (Option 1 in this study as presented below) would be to discretize every piece of impervious and pervious surface as an independent subcatchment. This promises a decrease in model output uncertainty (Krebs et al., 2014; Sun et al., 2014), but requires specifying all the modeling parameters and unique flow directions among all subcatchments, results in longer computational times, and produces data management burdens that are typically not practical. The opposite extreme would be a highly generalized subcatchment characterization where the entire area is modeled as one subcatchment with just two subareas, lumping all the spatial heterogeneity into a fictional space that has no basis in physical reality. Within this continuum, we chose to consider six plausible options for representing urban spatial constructs that are constrained by the SWMM subcatchment/subarea paradigm were examined (Fig. 5). As shown in the legend of Fig. 5, each rectangle represents a subcatchment in SWMM, and the dotted line divides subareas within the subcatchment. A rectangle without a dotted line means the subcatchment consists of a single (homogeneous) subarea, either $100 \%$ impervious or pervious. The arrows represent flow routing directions. Conducting this assessment at the watershed scale would not only be tedious and time consuming to configure, but could be inappropriate because of potentially confounding effects introduced when the drainage network and groundwater algorithm are included in the simulation. We felt it more rational to base our assessment of HRE setup options at the scale of an HRE, i.e., the area that drains to a storm sewer inlet, and judge the results in comparison to the most spatially explicit option. Note, we do not have supporting observational data at this scale to prove this assumption. This would require flow data at the point of entry to a storm sewer inlet, which is very difficult to obtain in practice.

Instead, a hypothetical representation of a typical urbanscape was defined as the HRE and used to model eight synthetic single storm events for each of the six setup options (Fig. 5). The hypothetical HRE is meant to represent a typical $4041 \mathrm{~m}^{2}$ (1 acre) residential area consisting of $809.4 \mathrm{~m}^{2}$ (0.2 acre) DCIA, $1214.1 \mathrm{~m}^{2}$ (0.3 acre) ICIA, and $2023.4 \mathrm{~m}^{2}$ (0.5 acre) PA. The DCIA consists of $607.0 \mathrm{~m}^{2}(0.15 \mathrm{acre})$

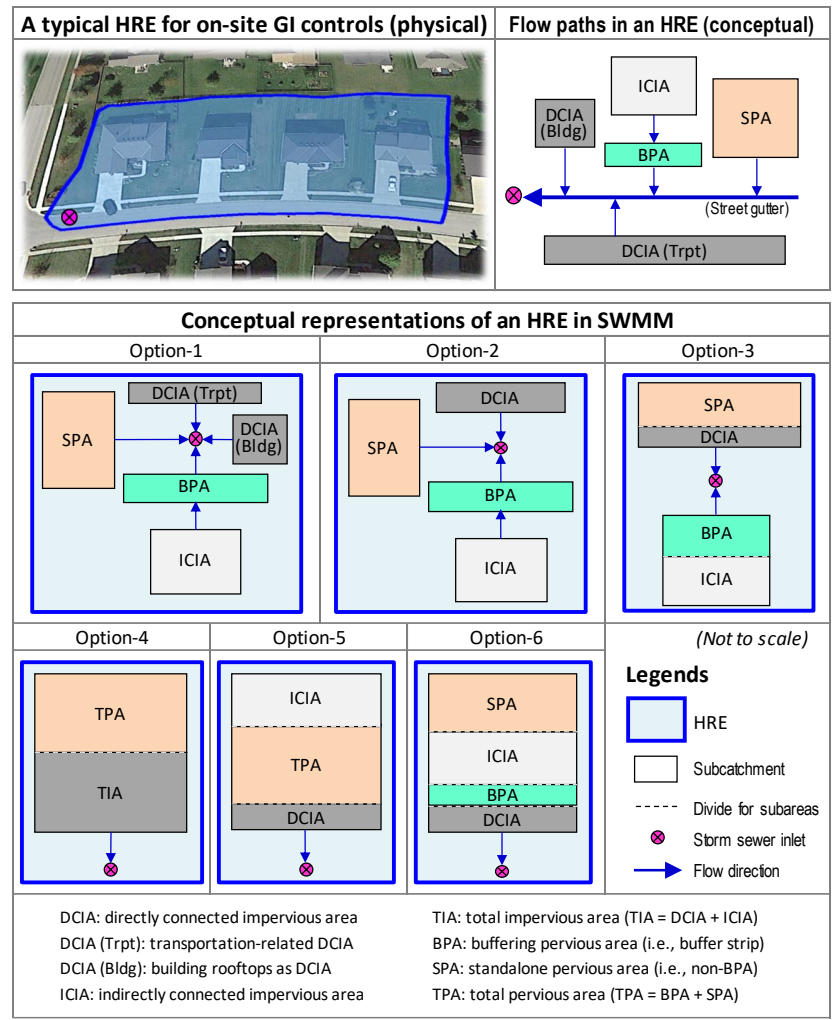

Figure 5. A conceptual representation of the hypothetical HRE (20\% DCIA, $30 \%$ ICIA, $10 \%$ BPA, and $40 \%$ SPA) and the six options considered for representing this area in the setup of a SWMM model.

transportation-related surfaces (e.g., streets, driveways) and $202.3 \mathrm{~m}^{2}$ (0.05 acre) building rooftops. The runoff from ICIA discharges through $404.7 \mathrm{~m}^{2}(0.1$ acre $) \mathrm{BPA}$, thus the SPA of the area is $1618.7 \mathrm{~m}^{2}(0.4$ acre $)$.

Referring to Fig. 5, in Option 1, five subcatchments are arranged for modeling the hypothetical HRE, separately modeling transportation DCIA (Trpt) and building DCIA (Bldg) along with ICIA, BPA, and SPA. DCIA is modeled with two subgroups because buildings have slanted rooftops while paved areas for transportation are basically flat in a typical residential area. This is the lowest level of spatial aggregation among the six options. This option would result in the highest number of subcatchments and, therefore, number of data requirements. Option 2 combines the two DCIA subcatchments in Option 1, resulting in four subcatchments set up for one HRE. In Option 3, the four subcatchments in Option 2 are aggregated into two subcatchments, and each subcatchment is configured with two subareas. The imperviousness and the flow direction between subareas per subcatchment need to be specified in SWMM with "\% imperv", "subarea routing", and "percent routed". The impervious option for subarea routing means runoff from pervious area flows to impervious area, whereas pervious does the oppo- 
Table 1. Initial and calibrated modeling parameters for the Shayler Crossing watershed. "n/a" indicates the parameter is not applicable to the land cover type.

\begin{tabular}{|c|c|c|c|c|c|c|c|c|c|c|}
\hline \multirow[t]{2}{*}{ Land cover } & \multicolumn{2}{|c|}{ Length (m) } & \multicolumn{2}{|c|}{ Slope $(\%)$} & \multicolumn{2}{|r|}{$n$} & \multicolumn{2}{|c|}{$\mathrm{DS}(\mathrm{mm})$} & \multicolumn{2}{|c|}{$K_{\text {sat }}\left(\mathrm{mm} \mathrm{h}^{-1}\right)$} \\
\hline & Initial & Calibrated & Initial & Calibrated & Initial & Calibrated & Initial & Calibrated & Initial & Calibrated \\
\hline Main building & 9.1 & 7.6 & 10 & 15 & 0.014 & 0.01 & 2.0 & 1.3 & $\mathrm{n} / \mathrm{a}$ & $\mathrm{n} / \mathrm{a}$ \\
\hline Misc. building & 4.6 & 4.6 & 10 & 15 & 0.014 & 0.01 & 2.0 & 1.3 & $\mathrm{n} / \mathrm{a}$ & $\mathrm{n} / \mathrm{a}$ \\
\hline Street & 3.0 & 3.0 & 2 & 2.5 & 0.011 & 0.01 & 2.5 & 1.3 & $\mathrm{n} / \mathrm{a}$ & $\mathrm{n} / \mathrm{a}$ \\
\hline Driveway & 4.6 & 3.7 & 2 & 1.5 & 0.012 & 0.01 & 2.5 & 1.3 & $\mathrm{n} / \mathrm{a}$ & $\mathrm{n} / \mathrm{a}$ \\
\hline Parking & 3.0 & 3.0 & 1 & 1.5 & 0.012 & 0.01 & 3.0 & 1.3 & $\mathrm{n} / \mathrm{a}$ & $\mathrm{n} / \mathrm{a}$ \\
\hline Sidewalk & 0.9 & 0.9 & 1 & 1.5 & 0.012 & 0.01 & 3.0 & 1.3 & $\mathrm{n} / \mathrm{a}$ & $\mathrm{n} / \mathrm{a}$ \\
\hline Other impervious & 3.0 & 2.4 & 1 & 1.5 & 0.012 & 0.01 & 3.0 & 1.3 & $\mathrm{n} / \mathrm{a}$ & $\mathrm{n} / \mathrm{a}$ \\
\hline Lawn & 24.4 & 24.4 & 2 & 2 & 0.2 & 0.3 & 5.1 & 5.1 & 1.6 & 0.89 \\
\hline Forest & 24.4 & 24.4 & 3 & 2 & 0.6 & 0.6 & 10.2 & 7.6 & 1.6 & 1.52 \\
\hline Agriculture & 30.5 & 30.5 & 2 & 2 & 0.3 & 0.3 & 7.6 & 5.1 & 1.6 & 1.02 \\
\hline
\end{tabular}

site (Rossman, 2015). Percent routed should be specified as 100 for both subcatchments. In options 4 through 6 , the areas are further aggregated to a single subcatchment representation for an HRE in SWMM. Option 4 configures the single subcatchment with only two subareas, impervious and pervious areas. The runoff from pervious area discharges through impervious area (i.e., TIA = DCIA). In Option 5, DCIA and ICIA are independently modeled by specifying the subarea routing option as pervious and the percent routed as the ratio of ICIA/TIA. This option may be considered an unrealistic "green" development condition where runoff from ICIA is evenly distributed throughout the entire pervious area, which means the entire pervious area works like a buffer (i.e., TPA = BPA). Finally, in Option 6, LID controls in SWMM are used for modeling BPA and ICIA. BPA is modeled as a vegetated swale with a very small berm height, $2.54 \mathrm{~mm}(0.1 \mathrm{inch})$. In the "LID Usage Editor", the "area of each unit" specifies the size of BPA and the "\% of impervious area treated" is the fraction ICIA/TIA. With this configuration, the four hydrologically homogenous subareas - DCIA, ICIA, BPA, and SPA - are accounted for.

Lengths for overland flow (or sheet flow) were assumed to be $4.57 \mathrm{~m}$ ( 15 feet), $9.14 \mathrm{~m}$ ( 30 feet), $12.19 \mathrm{~m}$ ( 40 feet), and $15.24 \mathrm{~m}$ (50 feet) for transportation-related DCIA, building rooftops as DCIA, ICIA, and pervious area, respectively. The surface slopes of these were assumed to be 3,11,5, and $2 \%$, respectively. Surface dimensions and slopes of typical urban land cover components are based on construction codes or were inferred based on the GIS. The values selected are meant to represent typical residential areas in the United States. For example, the assumed values were derived using overland flow from the center of the street to the curb in a crowned $9.14 \mathrm{~m}$ (30 feet) wide neighborhood street with $3 \%$ cross-sectional slope for the crown, $18.29 \mathrm{~m}$ (60 feet) wide gable houses with $11 \%$ cross-sectional slope for the rooftops, and pervious surfaces with $2 \%$ slope on average. Every IA is modeled with 0.01 for Manning's roughness co-
Table 2. Profile of the selected eight $24 \mathrm{~h}$ single storm statistics.

\begin{tabular}{lrrr}
\hline Rain $(\mathrm{mm})$ & Frequency & Percentile & Cumulative \\
\hline 12.7 & $<1$ month & $64.8 \%$ & $32.7 \%$ \\
25.4 & $1-2$ months & $87.4 \%$ & $63.1 \%$ \\
36.8 & 3 months & $95.0 \%$ & $80.7 \%$ \\
48.3 & 6 months & $97.7 \%$ & $89.2 \%$ \\
61 & 1 year & $99.2 \%$ & $95.3 \%$ \\
73.7 & 2 years & $99.6 \%$ & $97.3 \%$ \\
108 & 10 years & $100 \%$ & $99.8 \%$ \\
149.8 & 50 years & $100 \%$ & $100 \%$ \\
\hline
\end{tabular}

The percentile and cumulative percentage-based statistics qualify the exceedance probability of each event and the relative contribution of events of similar size or lower to the annual rainfall, respectively.

efficient $(n)$ and $2.54 \mathrm{~mm}(0.1 \mathrm{inch})$ for depression storage (DS). Pervious area is modeled with 0.1 for $n$ and $5.08 \mathrm{~mm}$ (0.2 inch) for DS. Identical infiltration parameters were applied to all the options. In this hypothetical HRE model setup analysis, all of the six options were arranged using the same spatial and hydrologic characteristics. However, the ways DCIA, ICIA, BPA, and SPA were parameterized in SWMM were different among the options (Fig. 5).

Rainfall-runoff response is also affected by storm size, so we applied eight different $24 \mathrm{~h}$ single storms (Table 2) selected from a regional rainfall frequency report produced by the National Oceanic and Atmospheric Administration (NOAA) and the Illinois State Water Survey (Huff and Angel, 1992). Another data set was used to estimate the percentile and cumulative rainfall depths per year, i.e., annual statistics per $24 \mathrm{~h}$ storm. This data set covered about 35 years of hourly precipitation records from a local weather station in Milford, Ohio. A certain percentile rainfall event represents a precipitation amount that the same percent of all rainfall events for the period of record does not exceed (USEPA, 2009). The percentile values in Table 2 were estimated using the method presented in the same report (USEPA, 2009). 
For example, the 90th percentile rainfall event is defined as the measured precipitation depth accumulated over a $24 \mathrm{~h}$ period for the period of record that ranks as the 90th percentile rainfall depth based on the range of all daily event occurrences during this period. Values in the cumulative column of Table 2 represent the percentage of annual cumulative precipitation depth, which are less than or equal to the specific rainfall depth during a $24 \mathrm{~h}$ period. In SWMM, the selected storms were distributed with 5 min intervals by applying the Natural Resources Conservation Service (NRCS) Type-II distribution (USDA, 1986).

\subsection{Calibration of the SHC watershed SWMM model}

Stream flows were measured at the outlet from a rating curve using water depth recorded at $10 \mathrm{~min}$ intervals. A tipping bucket rain gauge measured rainfall depths at $10 \mathrm{~min}$ intervals, with a minimum detectable rainfall depth of $0.254 \mathrm{~mm}$ (0.01 inch). The SWMM model for SHC (Fig. 6) was run for a 6-month period (1 April 2009 to 31 August 2009) where the first 4 months of this period were used to stabilize the continuous simulation, in particular for the groundwater simulation. This is defined as the model warm-up period, which is the time period required to achieve a stable condition wherein the groundwater level ceases to increase or decrease by a specified initial parameter threshold value. After the warm-up period, the last 2 months, from July to August 2009, were used for model calibration. Model calibration was done manually by adjusting the initial values for the 10 land cover types and using the different sets of BPA (see Fig. 3). Changes were integrated one at a time into every subcatchment using the area-weighting approach in an Excel spreadsheet. The calibrated modeling parameters for individual land cover types are given in Table 1 alongside their initial values. An Excel worksheet was created with embedded lookup and averaging functions so that changes made to the original values in Table 1 or switches between BPA sets configured using the different buffer distances could be easily propagated to changes in the related parameter values used in the SWMM model using the SWMM Excel Editor function. With this approach, the calibration effort is evenly applied to the urban land cover types, which in turn are propagated to the parameterization of all subcatchments, instead of calibrating parameters individually for each subcatchment. This methodology assumes that urban land cover components are generalizable and independent from scale even though the subcatchments themselves are not generalizable or easily scalable. Also, notable about this approach, the parameter calibration domain remains the same even if the total number of subcatchments is increased and/or the size of watershed area is increased. If a land cover type does not maintain a sufficient level of homogeneity across the watershed under study, we would need to divide the land cover into subcategories and use more than one set of parameters for the land cover type in each category. For example, the main building can be divided into two subcategories that represent slanted rooftops and flat rooftops independently, and the lawn area can be divided into multiple subcategories based on different surface slopes and/or soil infiltration properties. This can be handled by spatial analysis in GIS by overlaying land use, topography, or soil property data with the land cover layer.

Sensitivity analysis was conducted for the modeling parameters of width, slope, $n$ and DS for IA, $n$ and DS for PA, $K_{\text {sat }}$, and the size of BPA. Each parameter was decreased and increased 5, 10, and $20 \%$, respectively, one at a time, and in separate model runs. The sensitivity of each parameter was estimated as

Sensitivity $=(\Delta \mathrm{MR} / \mathrm{MR}) /(\Delta p / p)$,

where MR is the modeling result in units of flow volume from the SWMM run, $\triangle \mathrm{MR}$ is the change in SWMM modeling result based on change in parameter value, $p$ is the parameter value, and $\Delta p$ is the change in parameter value.

\subsection{Modeling GI scenarios}

GI scenarios are added to the model using the land cover database, soils, storm sewer systems, and GIS techniques to derive relevant BPA and may require some field investigation to ground-truth the options. The general workflow for GI modeling is presented in the bottom half of Fig. A1. Implementing GI can be achieved by adjusting the hydrologic properties of individual land cover components, such as converting lawn area to shrub or forest (Lee et al., 2005). This sort of GI implementation can reduce the volume, peak, and speed of surface runoff and be modeled by adjusting DS, slope, $n$, or overland flow length for the converted land cover component. The one scenario we examined was decreasing DCIA by disconnecting the directly connected rooftop downspouts that directly route flow from the main buildings to the sewer system. This effectively reclassifies main buildings as ICIA. After the downspouts are disconnected, the PA that receives stormwater runoff from the disconnected rooftop now works as additional BPA. To model this additional buffering capacity, the size of BPA is re-estimated and the percent of IA routed to BPA is changed in SWMM. The increase in size of the BPA under this GI scenario was estimated again using the spatial analysis tools in ArcGIS by changing the buffering distance value from the calibrated baseline value of $0.61 \mathrm{~m}$ ( 2 feet) to $3.1 \mathrm{~m}$ (10 feet) around ICIA, including the disconnected main buildings. As a result, the modeled GI scenario includes two types model changes: one that reflects the downspout disconnection and another the buffering area extension.

The characteristic width per subcatchment is a computed value that is usually treated as a calibration parameter in SWMM (see Appendix). Under conventional stormwater management modeling approaches, once the width value is set, it is not adjusted during management scenario analysis. However, GI, by design, changes the flow path lengths and 


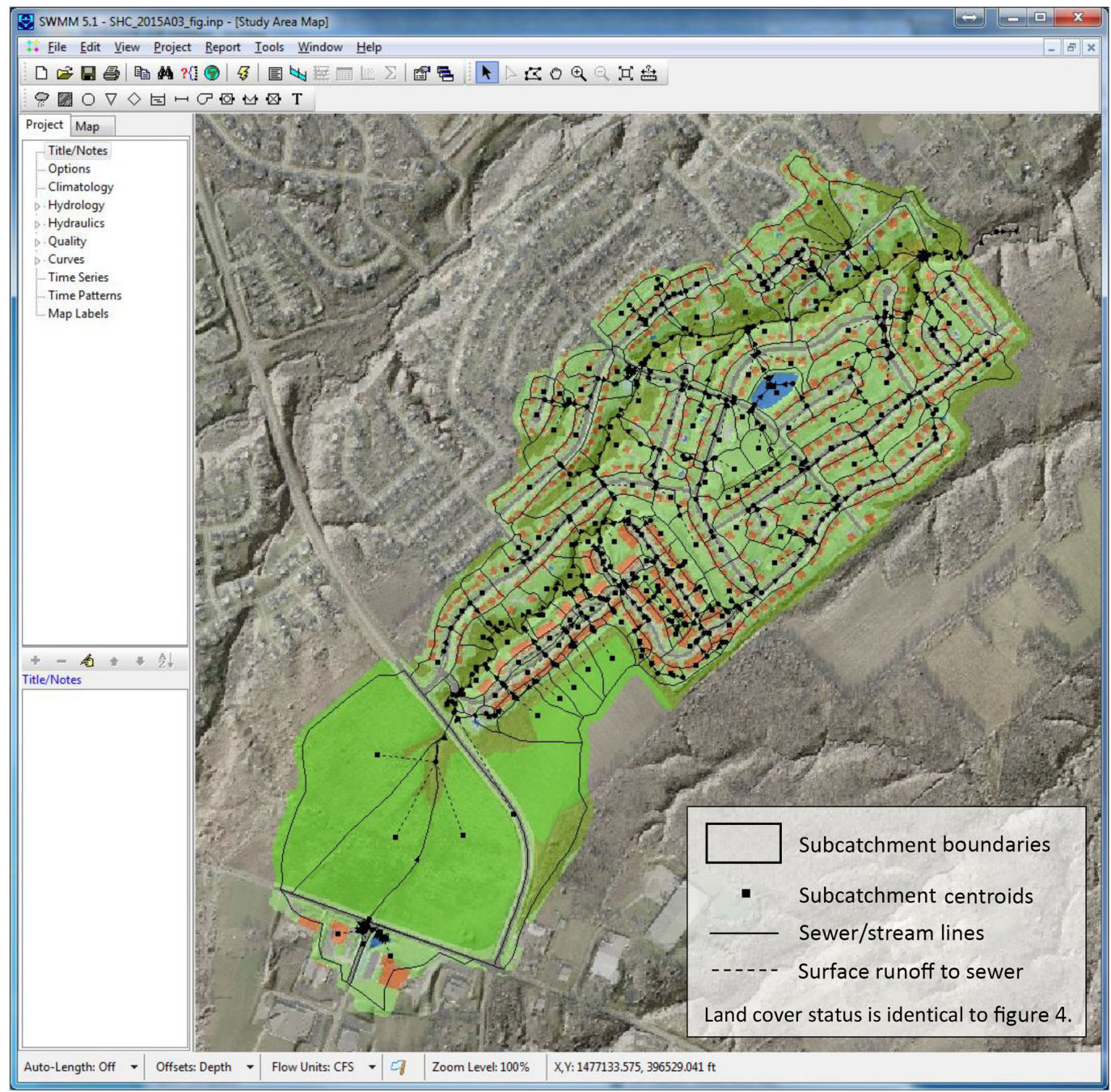

Figure 6. Diagram of the developed SWMM model for the Shayler Crossing watershed.

therefore the computed value of the width parameter as represented in SWMM should also change. The methodology we present here provides a systematic way of changing the width parameter in a rational and objective manner to account for the modeled GI scenario. Unfortunately, the suitability of this modeling approach cannot be determined until a high density of GI has been implemented at a watershed scale with before and after field observations.

\subsection{Hydrograph separation}

With the approach taken for the SWMM setup for both the baseline and GI scenario analysis adjustments can be made to apportion the simulated storm hydrologic loading from the watershed among the dominant sources: DCIA, ICIA+BPA, SPA, and subsurface flow. This can provide further insight into the effects of GI on watershed hydrology. For this purpose, the output from four SHC-SWMM runs were generated:
- Run 1: every subcatchment is specified as described under Option 6 (as conceptually represented in Fig. 7a) with groundwater options parameterized to represent the base SWMM model.

- Run 2: groundwater options were excluded from the base model setup to remove any subsurface flow contributions to the stream flow hydrographs. The difference between (1) and (2) represents the stormwater contributions to the stream as subsurface flow from the watershed.

- Run 3: to estimate surface runoff from all impervious areas (i.e., runoff from DCIA, plus ICIA through BPA) in the models without the groundwater, the SPA was also omitted from every subcatchment (Fig. 7b).

- Run 4: to estimate surface runoff from DCIA, only DCIA was modeled in this run (Fig. 7c). 

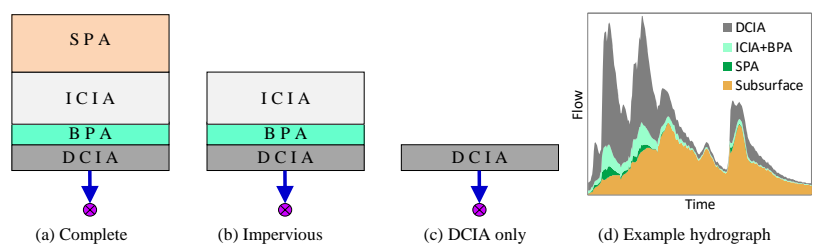

Figure 7. Conceptual representations of discrete SWMM models for hydrograph separation.

An example result of the hydrograph flow pathway separation is presented in Fig. 7d, and the process is summarized mathematically as follows:

$$
\begin{aligned}
& Q_{\text {total }}=Q_{\mathrm{DCIA}}+Q_{\mathrm{ICIA}+\mathrm{BPA}}+Q_{\mathrm{SPA}}+Q_{\text {subsurface }}, \\
& Q_{\text {surface }}=Q_{\mathrm{DCIA}}+Q_{\mathrm{ICIA}+\mathrm{BPA}}+Q_{\mathrm{SPA}}, \\
& Q_{\text {subsurface }}=Q_{\text {total }}-Q_{\text {surface }} \\
& Q_{\mathrm{SPA}}=Q_{\text {surface }}-Q_{\text {imperv }}, \\
& Q_{\mathrm{ICIA}+\mathrm{BPA}}=Q_{\text {imperv }}-Q_{\mathrm{DCIA}},
\end{aligned}
$$

where $Q_{\text {total }}$ is the total runoff with groundwater flow in SWMM, $Q_{\text {surface }}$ is the surface runoff without groundwater flow, $Q_{\text {imperv }}$ is the runoff from impervious area (DCIA and ICIA through BPA), $Q_{\text {DCIA }}$ is the runoff from DCIA only, $Q_{\text {ICIA+BPA }}$ is the runoff from ICIA and BPA, $Q_{\text {SPA }}$ is the runoff from SPA only, and $Q_{\text {subsurface }}$ is the runoff through groundwater flow (i.e., subsurface or lateral flow).

\section{Results and discussion}

The SHC watershed model parameter values pre- and postcalibration are presented in Table 1 .

\subsection{Spatial analysis}

Table 3 reveals the results of the detailed spatial analysis conducted using the described GIS techniques. The fractional DCIA for buildings, streets, driveways, parking areas, and sidewalks are $96.1,79.5,94.2,42.8$, and $14.2 \%$, respectively. Overall, the study watershed is covered by $18.8 \%$ DCIA, and three sets of BPA were derived for $0.30,0.61$, and $1.52 \mathrm{~m}$ buffer lengths. After calibration, the $0.61 \mathrm{~m}$ buffer around ICIA was selected for SHC. This means that the runoff from ICIA is discharged to the adjacent pervious area with $0.61 \mathrm{~m}$ buffer width, based on runoff volume and timing in hydrographs (see Figs. 10 and 11). This existing buffer covers $22683.5 \mathrm{~m}^{2}$ of the pervious area, which is $2.3 \%$ of the entire watershed and $3.0 \%$ of the pervious area. As the baseline, the SHC watershed consists of $18.8 \%$ DCIA, $5.2 \%$ ICIA, $2.3 \% \mathrm{BPA}, 73.1 \% \mathrm{SPA}$, and $0.6 \%$ water. Under the modeled GI scenario of disconnecting rooftop drains and extended BPA, the DCIA is reduced to $9.6 \%$, the ICIA increases to
$14.4 \%$, the BPA increases to $17.2 \%$, and the SPA is reduced to $58.2 \%$ of the total area, respectively.

\subsection{The hypothetical HRE modeling analysis}

The eight single storm hypothetical HRE modeling analysis with the six discretization options resulted in 48 SWMM runs. As explained earlier, this was done to determine which HRE configuration option best balances model complexity and presumed accuracy. Each simulated storm was assumed to last from midnight to midnight. Results are presented as hydrographs between 11:00 and 13:00 where most concentrated rainfall occurs in the NRCS Type-II distribution (USDA, 1986) (Fig. 8). In large storms, larger than a 5-year storm in particular, all six types of spatial discretization produce very similar hydrographs as shown in Fig. $8 \mathrm{~g}$, h. The modeled flow rates and total runoff volumes are almost identical.

In the large storm situation, all of the PAs are saturated in the early stage of the storm. Once saturated, the PAs are not able to provide any additional on-site hydrologic control and behave as IA. In view of this, any of the spatial discretization options would be suitable for analyzing flood controls and in designing a drainage system based on a 10 -year storm. However, this is not the relevant case for evaluating GI implementation, which focuses on controlling smaller storms. For storms smaller than a 2-year event, considerable differences were found among the simulated hydrographs (Fig. 8a-e).

In the smallest storm situation (Fig. 8a) the options for spatial discretization result in almost identical hydrographs except Option 4, where only DCIA discharges runoff, as the total impervious area (TIA) is modeled as DCIA. Rainfall onto PA is completely captured by DS and/or infiltrated to the soils. Because Option 4 ignores the difference between DCIA and ICIA, the entire impervious area (subarea IA) is modeled the same as DCIA, which means all of the runoff is discharged to the storm drainage system directly with no abatement. Under a small storm (like $<1$-month storm), runoff occurs only from IA - more specifically, only from DCIA. For small storms, runoff from ICIA is completely controlled by BPA (if ICIA exists), but no ICIA is modeled under Option 4. Because of this, modeled runoff from this option is higher than any of the other options under the small storms. DCIA is modeled explicitly in the other five options. The relative difference in runoff estimates caused by modeling TIA as DCIA contribution diminished as larger storms are modeled, Fig. 8a-c. Option 4 is not suitable to modeling GI alternatives because it ignores the significance of characterizing DCIA and ICIA within an HRE. Option 5 shows the most significant variation among the simulated hydrographs. This option estimates lower flow rates than the others for smaller storms, but higher peaks in medium-size storms (such as 6month to 2-year return period storms; Fig. 8d-f). Option 5 is configured to simulate the "ideal" green implementation scenario of surface grading for stormwater discharge, in which 
Table 3. Land cover status of Shayler Crossing watershed.

\begin{tabular}{llrrrr}
\hline \multicolumn{2}{c}{ Surface components } & DCIA $\left(\mathrm{m}^{2}\right)$ & ICIA $\left(\mathrm{m}^{2}\right)$ & Sum $\left(\mathrm{m}^{2}\right)$ & Fraction \\
\hline Impervious areas & Building & 91770.0 & 3756.2 & 95526.2 & $9.6 \%$ \\
& Street & 57610.5 & 14897.2 & 72507.7 & $7.3 \%$ \\
& Driveway & 33554.7 & 2083.7 & 35638.4 & $3.6 \%$ \\
& Parking & 2362.7 & 3154.1 & 5516.8 & $0.6 \%$ \\
& Sidewalk & 1646.9 & 9990.3 & 11637.2 & $1.2 \%$ \\
& Miscellaneous & - & 17766.8 & 17766.8 & $1.8 \%$ \\
& Sum of IA & 186944.7 & 51648.4 & 238593.1 & $24.0 \%$ \\
\hline Pervious areas & Lawn & & & 400667.4 & $40.3 \%$ \\
& Agriculture & & & 219430.4 & $22.1 \%$ \\
& Forest & & & 128558.1 & $12.9 \%$ \\
& Sum of PA & & & 748655.9 & $75.4 \%$ \\
\hline Water & Wet pond & & 5014.2 & $0.5 \%$ \\
& Swimming pool & & 698.9 & $0.1 \%$ \\
& Sum of water & & 6013.0 & $0.6 \%$ \\
\hline
\end{tabular}

the entire pervious area works like BPA. The expanded onsite pervious buffer can thoroughly control runoff from ICIA until the DS and infiltration capacity of BPA are fully saturated. Once the hydrologic capacities for on-site controls are fully saturated, the entire PA hydrologically responds more or less like IA. Once a subcatchment DS fills and exceeds infiltration capacity, this unrealistic green development condition may result in higher peak discharges than the other options.

From the hypothetical modeling analysis, it can be surmised that an extensive on-site green infrastructure implementation could result in more frequent local flooding, e.g., water intrusion into basements. This may be especially the case when evaluating scenarios for locations where mediumsize storms have a long duration, like during the wet season of the Pacific Northwest of the United States. The comparatively high runoff estimated for Option 5 (Fig. 8d-f) would be maintained until all PA is saturated by increased rainfall intensity. If a smaller portion of PA is modeled as BPA, while all the other conditions are kept the same, the BPA reaches the saturated condition under a smaller storm. Once the BPA is saturated the area hydrologically responds like IA. However, SPA (i.e., non-buffering pervious area) can still control rainfall within the area. This analysis suggests that it is important to properly define the area of BPA especially when analyzing GI alternatives for on-site stormwater controls, as we surmised originally. Therefore, Option 5 is not suitable for modeling a GI scenario because it ignores the actual significance of variance in BPA. It is a common modeling practice in SWMM to treat all pervious area the same (as in options 4 or 5 in Fig. 5), even though only the BPA can receive water from ICIA. As shown in Fig. 8, simulated runoff by options 4 or 5 would presumably be inaccurate, especially for the $<1$-year small storms.

Figure 9 contains graphs comparing the results among the six options (Fig. 5), showing the relative difference for peak flow, average flow, and total runoff volume for each of the five other options compared to Option 1, presumably the most accurate one, in terms of output uncertainty because the level of spatial lumping is the lowest.

The relative differences reported in Fig. 9 ("variation from the result of 5-subs" in the $y$ axis) were estimated as $\left(\mathrm{MR}_{j}^{k}-\right.$ $\left.\mathrm{MR}_{5 \text { subs }}^{k}\right) / \mathrm{MR}_{5 \text { subs }}^{k}$, where $\mathrm{MR}_{j}^{k}$ represents a modeling result from the $k$ th synthetic storm with the $j$ th discretization option and 5subs means the discretization with five subcatchments (i.e., Option 6). Options 1, 2, and 3 types of multisubcatchment discretization present similar hydrologic responses for all storm sizes. In comparison, both options 4 and 5 result in significantly different hydrologic outcomes, particularly for smaller storms. Again, this is due to the unresolved spatial delineation of DCIA from TIA and BPA from the total pervious area (TPA), respectively, whereas Option 6 is based on a single-subcatchment approach, but produces similar results to the multi-subcatchment discretization approaches under options 1, 2 and 3, for all storm classes tested. The differences between Option 6 and Option 1, though worth noting, are marginal for the three important hydrologic characteristics (Fig. 9). This outcome of the hypothetical analysis supports our original rationale for the relevance of characterizing the BPA. Under Option 6, the four critical hydrologic components (i.e., DCIA, ICIA, BPA, and SPA) are distinctly modeled in SWMM within a single subcatchment that is delineated based on the actual drainage area to a storm sewer inlet (termed an HRE in this study). Based on the results, Option 6 balances the combination of discretiza- 


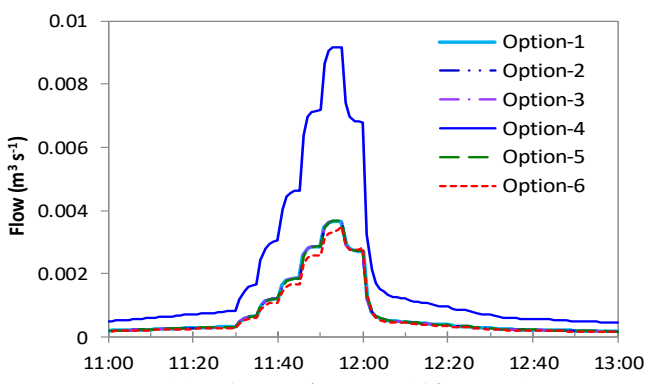

(a) $<1$ month storm $(12.7 \mathrm{~mm})$

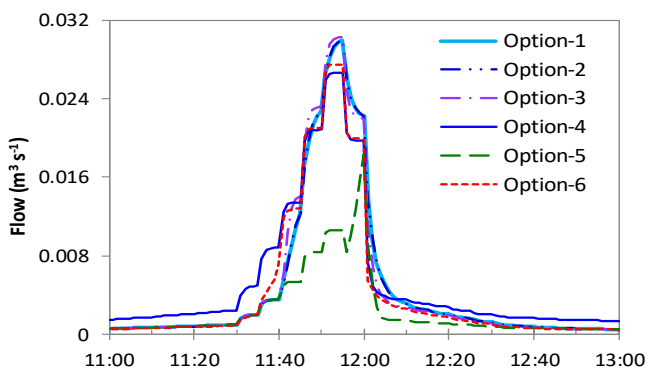

(c) 3 months storm $(36.8 \mathrm{~mm})$

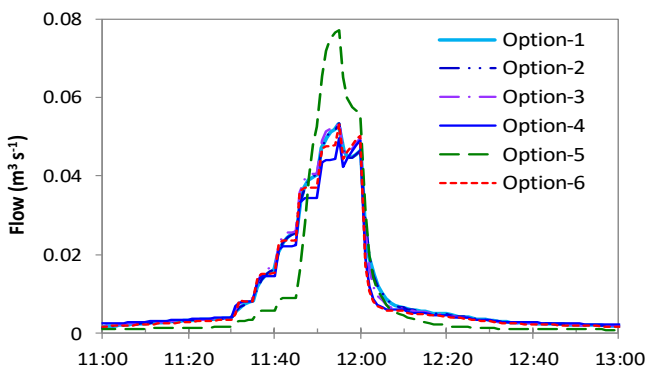

(e) 1 year storm $(61.0 \mathrm{~mm})$

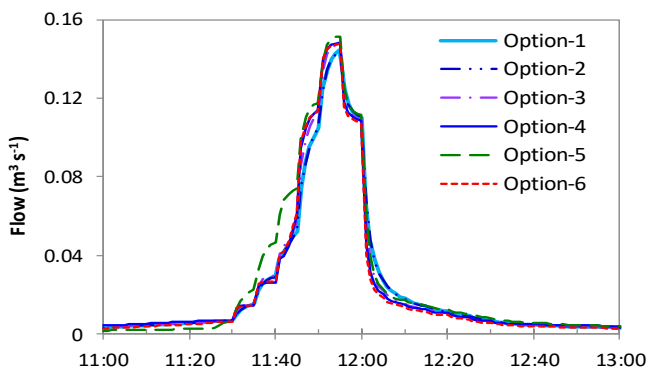

(g) 10 years storm $(108.0 \mathrm{~mm})$

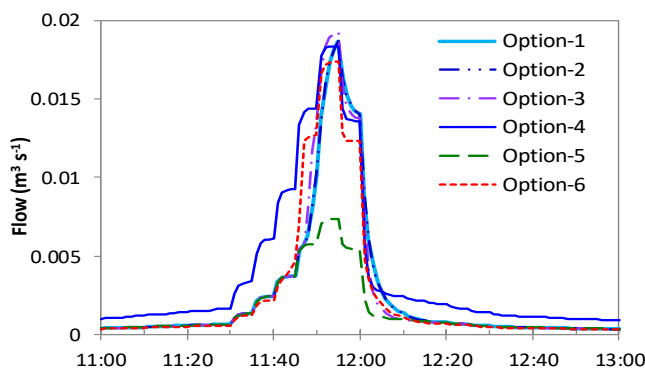

(b) 1-2 months storm $(25.4 \mathrm{~mm})$

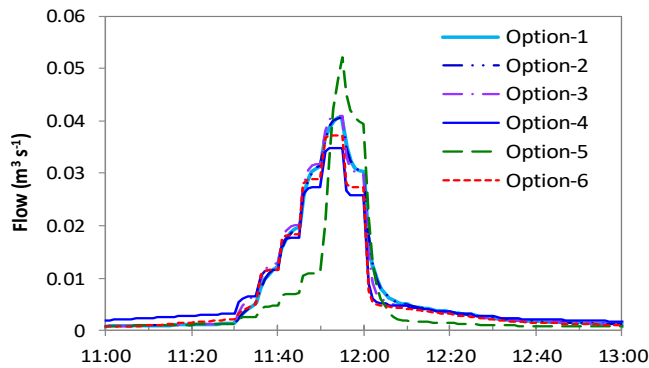

(d) 6 months storm $(48.3 \mathrm{~mm})$

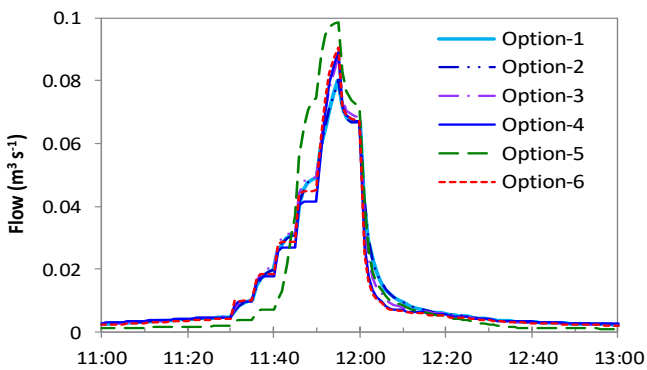

(f) 2 years storm $(73.7 \mathrm{~mm})$

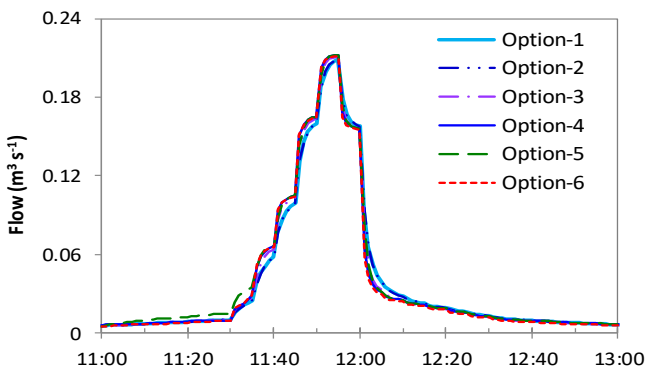

(h) 50 years storm $(149.8 \mathrm{~mm})$

Figure 8. Hypothetical HRE SWMM modeling results.

tion criteria, especially in terms of the level of effort required in model setup, configuring parameter values and output uncertainty.

\subsection{SHC watershed-scale modeling results}

Option 6 (Fig. 5) was used to set up the SWMM model for the SHC watershed as described above. The SHC model consists of 191 subcatchments and 269 junctions and con- duits (Fig. 6). The model also includes two wet ponds, two dry ponds, and a 10-year detention area modeled as storage structures with orifice-type hydrologic controls. The results of the model sensitivity analysis were summarized for the period 22 to 24 July 2009, using the total runoff volume as the endpoint being assessed with Eq. (2) (Fig. 10). There was a total of $164.6 \mathrm{~mm}$ rainfall during the 3 days of this period; this storm is smaller than the 1-year return period design storm $\left(61.0 \mathrm{~mm} \mathrm{~d}^{-1}\right)$ but larger than the 6-month storm 


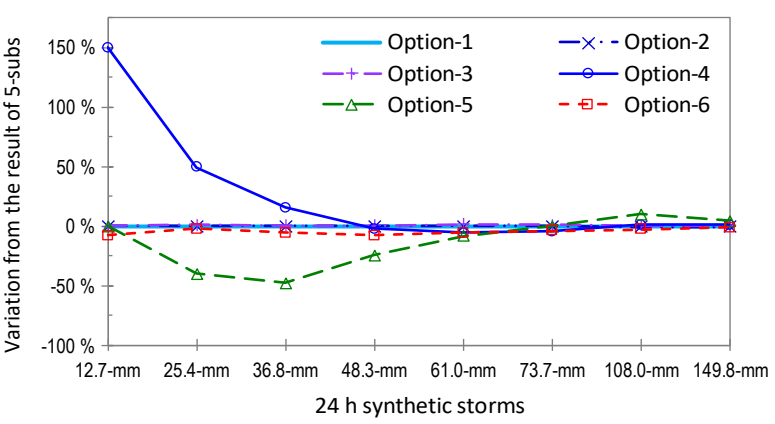

(a) Average flow rate

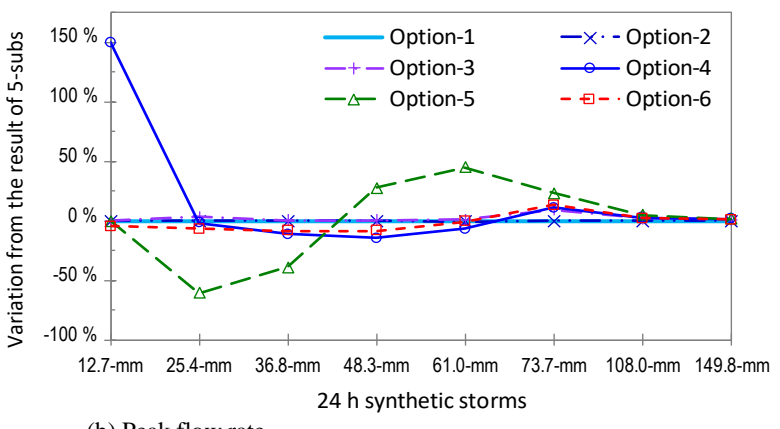

(b) Peak flow rate

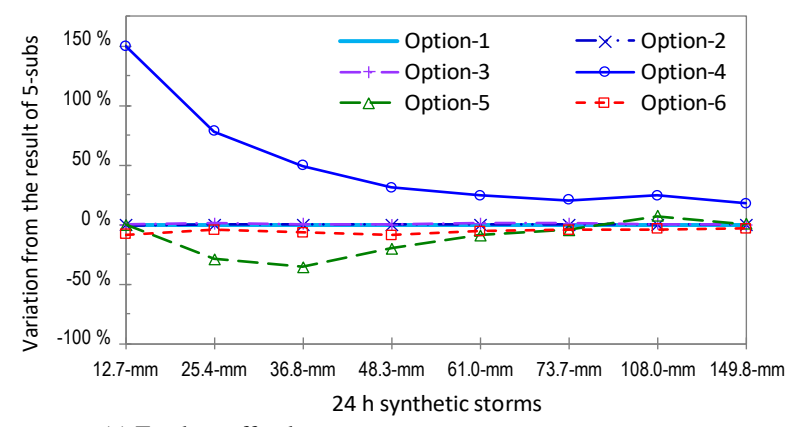

(c) Total runoff volume

Figure 9. Comparison of the hypothetical HRE modeling results.

$\left(48.3 \mathrm{~mm} \mathrm{~d}^{-1}\right)$ based on the storm statistics for the study area (see Table 2). While the $3 \%$ change in total runoff is not significant in sensitivity, the most sensitive parameter was $K_{\text {sat }}$, followed by BPA and DS. Whereas the changes in $K_{\text {sat }}$ affect the entire PA (75.4\% of SHC), the changes in BPA affect a much smaller area (2.3\% of SHC for the baseline condition) than PA. The other parameters (i.e., width, slope, and n) were found not to be as sensitive, with negligible changes in results $\leq \pm 0.15 \%$ even for $\pm 20 \%$ change in the individual parameter value. When land cover status is represented accurately in a SWMM model, certain parameters will be less sensitive because of the underlying hydraulic and spatial realities are well represented. For example, the parameters representing the impervious land cover types in this modeling analysis were found to be less sensitive than pervious area parameters.

Model calibration was conducted by adjusting the landcover-based modeling parameters and BPA to the entire

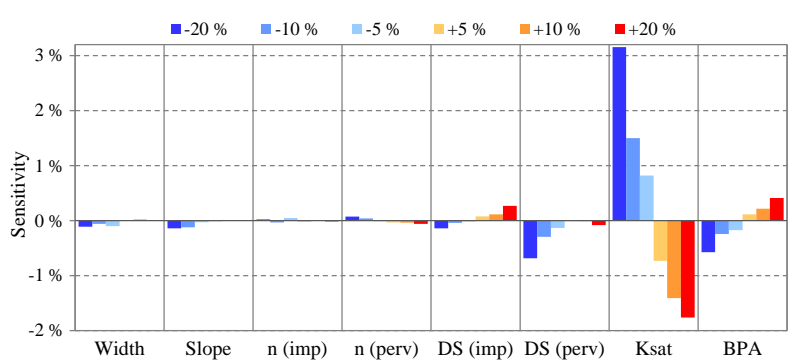

Figure 10. Sensitivity analysis of the SWMM parameters at SHC.

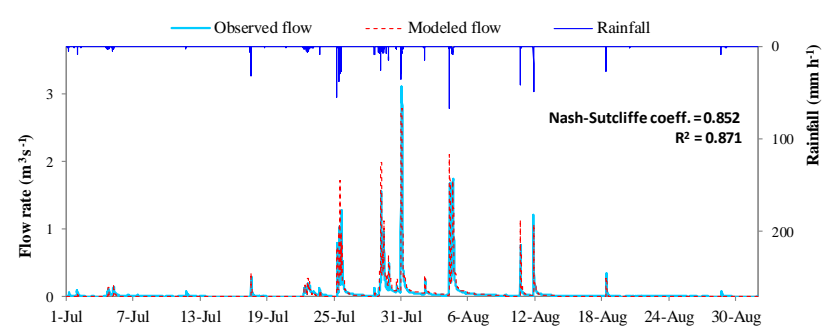

Figure 11. Watershed-scale SWMM modeling results from 1 July 2009 to 31 August 2009.

study watershed. As shown in Table 1, parameters for the impervious land cover types changed little and were made equivalent for $n$ and DS. As expected, parameters for the pervious land cover types needed more adjustment than those for the impervious. The initial value of $K_{\text {sat }}$ was defined using the site-specific soil types (mainly silty loam clay), but the values for the individual pervious land cover types were varied by the model calibration effort. Whereas $K_{\text {sat }}$ for forest area was adjusted only slightly (i.e., 1.6 initially to 1.52 for the final calibration), the values for lawn (or landscaped area) and agriculture required more adjustment (from 1.6 initial to 1.02 for agriculture, and from 1.6 initial to 0.89 for lawns). The relatively large changes for $K_{\text {sat }}$ are indicative of more soil compaction for urban and agricultural soils compared to the expected native soil condition.

The measured rainfall intensities and stream flow rates, along with the calibrated model results are presented in Fig. 11. The modeled hydrographs are well matched with the measured data at the watershed scale with a Nash-Sutcliffe coefficient $=0.852$ and $R^{2}=0.871$.

After making the model adjustments for the GI scenario, the relative percentages of the four classified subareas changed (Fig. 12a). Using the hydrograph separation approach, the relative contributions of the primary hydrologic components with and without GI implementation were estimated for the period 1 July 2009 to 31 August 2009 (Fig. 12b). A more-detailed representation for the hydrograph separation is presented in Fig. 13, which covers $72 \mathrm{~h}$ from 22 to 24 July 2009. It is interesting to note from Fig. 13 that the peak flow for the event depicted in the figure is 


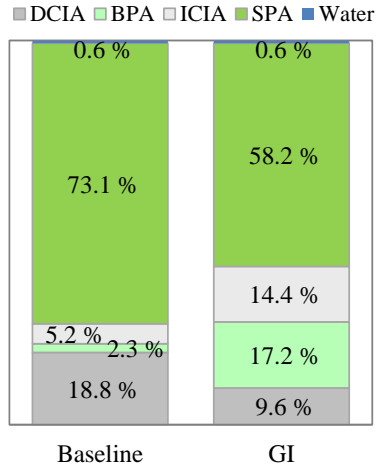

(a) Land cover components

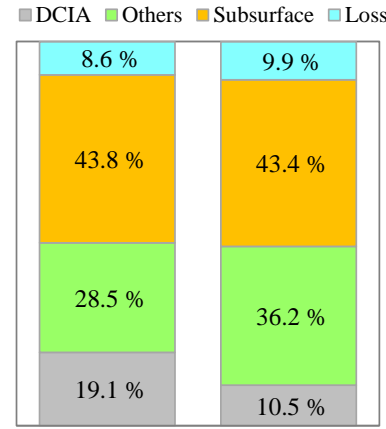

GI

period, even though the study watershed is characterized with poorly infiltrating soils. After applying the GI scenario, although the subsurface flow contributed a similar fraction to the stream flow, the fractional contributions of surface runoff from DCIA and the other areas are significantly changed (Figs. 12b and 13). This situation arises not from a change in land cover but the internal flow paths taken by the runoff. The result is reduced runoff from DCIA but increased runoff from the other areas (i.e., ICIA, BPA, and SPA).

From a water quality management perspective, it is necessary to consider hydrologic and contaminant discharge processes with respect to their sources and transport pathways. For example, if the watershed has water quality issues related to nutrients, the management effort might pay more attention to the stormwater discharge from pervious areas that include fertilizer applications. If GI were designed to intercept runoff from DCIA in the watershed, an unintended consequence could result from increased runoff volume traveling through a pervious area with elevated standing stocks of soluble or erodible nutrients. In this case, it would be important to consider turf management practices.

Another example of how the hydrograph separation approach (Fig. 13) provides additional opportunities for interpreting hydrodynamics before and after applying the GI scenario is revealed by considering that disconnecting downspouts reduced the total runoff volume, but also resulted in a higher peak flow (note the 16:00 time point on 22 July 2009 in Fig. 13). This result is like the single storm analysis using Option 5 (Fig. 5). Overall the flow volume is reduced from the GI scenario. However, when the peak occurred around 15:30 (shown in Fig. 13), the capacity of the GI for controlling stormwater was already exceeded because of controlling runoff during the previous rainfall that occurred between 7:00 and 14:00. Under this saturated condition, even the direct rainfall to the GI area will be discharged with minimum abatement. If there is no GI (as in the baseline condition), the same area receives only direct rainfall, there is no additional runoff from the impervious area, and that rainfall is controlled by still-available surface depression storage and notsaturated infiltration capacity. In the 22 July 2009 situation, the stormwater control capacity (mainly DS and infiltration) of the extended BPA is saturated by earlier rainfall. Once saturated, the BPA discharges higher runoff. The modeled GI contributes much higher runoff volume from PA, which might be nutrient enriched. With the hydrograph separation analysis, we gain insight to the consideration of stormwater management objectives and extend the utility of SWMM.

\section{Summary and conclusions}

We demonstrate how high-resolution spatial data can be applied to spatially discretize a watershed and develop a methodology that should decrease model output uncertainty with reduced calibration effort. The suitability of the spatial 
discretization approach for GI modeling was initially verified with a hypothetical urbanscape analysis using eight synthetic storms of various sizes. We evaluated our approach to SWMM subcatchment parameterization using the hypothetical analysis that allowed for the qualification of five different options relative to one that would be considered the most spatially explicit and, therefore, result in the least amount of output uncertainty (see Fig. 9). From the hypothetical analysis, the best option was selected to develop a watershed-scale SWMM model at the study area. The simulated hydrographs by the developed watershed-scale SWMM model were well matched with observed data over a 2-month continuous simulation (Nash-Sutcliffe coefficient $\left.=0.852 ; R^{2}=0.871\right)$ after minimal calibration effort. A GI scenario that modeled downspout disconnection from all the main buildings that are DCIA was described. We demonstrate how simple model adjustments can be made to separate the total and surface runoff among primary pathways that runoff takes before discharging to the natural stream network. This hydrograph separation procedure can shed light on GI design requirements and water quality management.

The optimal spatial discretization scheme distinguishes DCIA from ICIA, and BPA from SPA, and explicitly models these as subareas within each subcatchment parameterization in SWMM. This approach is particularly useful when modeling the impact of small storms, i.e., when BPA can control all or most of ICIA runoff. The land-cover-based spatial discretization approach is scale-independent, can be applied directly to a larger watershed as long as any heterogeneity in landscape properties is accounted for in the GIS setup (e.g., by dividing land cover components into multiple subgroups such as flat and slanted rooftops, high and low sloped urban hillslopes, or B and C type hydrologic soil types), and affords the opportunity to evaluate urban stormwater management strategies with presumably decreased output uncertainty for small storms and expanded applicability to GI planning, design, and implementation. Parameters are adjusted per SWMM subcatchment in a typical calibration approach, which is scale-dependent and requires more effort in larger watersheds. In our approach, a SWMM model is calibrated by adjusting parameters per land cover component, which are categorized by urban development codes or general construction specifications for land uses. Overall this study demonstrates the relative effectiveness of different approaches in drainage area characterization using highly resolved spatial data to the setup and analysis of a SWMM model that should improve its utility for simulation of GI.
Data availability. The data will be accessible via the US EPA's Environmental Dataset Gateway (https://edg.epa.gov/metadata/ catalog/main/home.page).

Competing interests. The authors declare that they have no conflict of interest.

Disclaimer. The US Environmental Protection Agency, through its Office of Research and Development, funded, managed, and collaborated in the research described herein. It has been subjected to the Agency's administrative review and has been approved for external publication. Any opinions expressed in this paper are those of the author(s) and do not necessarily reflect the views of the Agency; therefore, no official endorsement should be inferred. Any mention of trade names or commercial products does not constitute endorsement or recommendation for use. 


\section{Appendix A: Miscellaneous procedures for SWMM modeling for GI analysis}

For a full description of the steps used to set up a SWMM model for GI analysis using the methods outlined here see Lee et al. (2017), which is available for free download from the USEPA at https://nepis.epa.gov/Exe/ZyPDF.cgi/ P100TJ39.PDF?Dockey=P100TJ39.PDF, (last access: 20 April 2018). The procedure for developing the baseline model is schematically diagrammed in Fig. A1. To reduce model complexity, the original 16 land cover types (mentioned in Sect. 2.2.2) were reduced to 10 by merging the paved walking paths, patios, and miscellaneous impervious areas with other impervious areas; the dry ponds were merged with lawn areas; the detention area was merged with forest; and the surface areas for wet ponds and pools were modeled as IA without DS. The structures of the dry ponds, detention areas, and wet ponds were modeled as SWMM storage units. The final 10 land cover classifications include main buildings, miscellaneous buildings, streets, driveways, parking, sidewalks, other impervious areas, lawn, forest, and agriculture.

\section{A1 Determining values for SWMM subcatchment parameters: area-weighting approach}

Unique values for representing the corresponding area, width, slope, imperviousness, $n$, DS, and infiltration parameters ( $K_{\text {sat }}$, Suct, and IMD for the Green-Ampt option) were defined per SWMM subcatchment using GIS and a spreadsheet.

The area of each land cover type within a subcatchment was estimated using ArcGIS. The SWMM parameter "characteristic width" was estimated using an area-weighted flow length, as recommended in the SWMM Applications Manual (Gironás et al., 2009). This manual suggests, "If the overland flow length varies greatly within the subcatchment, then an area-weighted average should be used." Comparatively, in conventional SWMM modeling, the characteristic width is computed by dividing the subcatchment area by the average maximum overland flow length. Then adjustments are made to the characteristic width during model calibration to produce the best fit to the measured runoff hydrographs. The following area-weighting calculation describes how the characteristic width for a SWMM subcatchment was estimated in this study, where $i$ represents all the individual land cover types within the subcatchment:

Length $=\Sigma\left(\right.$ Length $_{i}$ Area $\left._{i}\right) / \Sigma\left(\right.$ Area $\left._{i}\right)$,

Width $=\Sigma\left(\right.$ Area $\left._{i}\right) /$ Length.

Other parameters were also defined as area-weighted averages per subcatchment (e.g., slope and infiltration parameters) or subarea (e.g., $n$ and DS). This area-weighting step is used following the typical approach recommended to account for the spatial lumping that effectively averages patchy land cover types within SWMM subcatchments (Gironás et al., 2009; Rossman and Huber, 2016). Hence, the extent of each individual type of land cover in a subcatchment is used to area-weight the assigned parameter values. For example, if IA within a subcatchment consists of two building rooftops, two driveways, and one section of street, the associated IA in SWMM is assigned values for DS based on an area-weighted average using the corresponding nominal values presented in Table $1, \mathrm{DS}_{\mathrm{imp}}=\Sigma\left(\mathrm{DS}_{i} A_{i}\right) / \Sigma\left(A_{i}\right)$, where $\mathrm{DS}_{\text {imp }}$ is the assigned DS for the impervious subarea within the subcatchment, $A$ is the size of an individual impervious land cover type within the subcatchment, and $i$ is an individual land cover type. Calculations for area-weighting were all done in a Microsoft Excel spreadsheet that was configured for direct copy and pasting as the SWMM input file using the EPA-SWMM Excel Editor function (see Lee et al., 2017, for specifics and Fig. A1). Two sets of $n$ and DS were defined per SWMM subcatchment - one set for the impervious subarea and the other for the pervious subarea. Where available, relevant values were obtained from experience in the watershed or using GIS (e.g., overland flow length), or as suggested by the SWMM manual (Huber and Dickinson, 1988; Rossman, 2015). The SHC watershed has silty loamy clay soils throughout. Based on this soil type, Suct was set to be $165 \mathrm{~mm}$ using the SWMM User's Manual (Rossman, 2015). IMD was modeled using the default value (0.22) in the EPASWMM. The actual IMD is dynamically updated at every modeling time step. The developed SWMM model runs for a 6-month period where the first 4 months of this period are used to stabilize the continuous simulation (i.e., the warmup period). Hence, the IMD value when modeling results are first reported may not reflect the initial value assigned during model setup. The values for $K_{\text {sat }}$ were amended during the model calibration to comprise surface compaction in lawn, agricultural, and forest areas (Horton et al., 1994; Gregory et al., 2006). However, we did not try to change the values of Suct and IMD during the calibration. Although the status and spatial extent of each land cover type within each HRE are different, the parameter values were assigned independent of the HRE in which it resided (Table 1). This parameter assignment methodology at the level of land cover components reduces model complexity by minimizing the amount of subcatchment-specific parameterizations that may need to be considered during calibration.

\section{A2 Setting up the BPA}

The baseline BPA (that controls runoff from ICIA) was modeled by parameterizing the subcatchment LID controls of SWMM. The LID process "vegetated swale" was selected among the LID control options in SWMM as the most appropriate option to represent the actual BPA. The BPA area estimated from the geoprocessing steps described above was added as well as values for the width, initial saturation, and $\%$ of subcatchment imperviousness draining to the BPA. The 

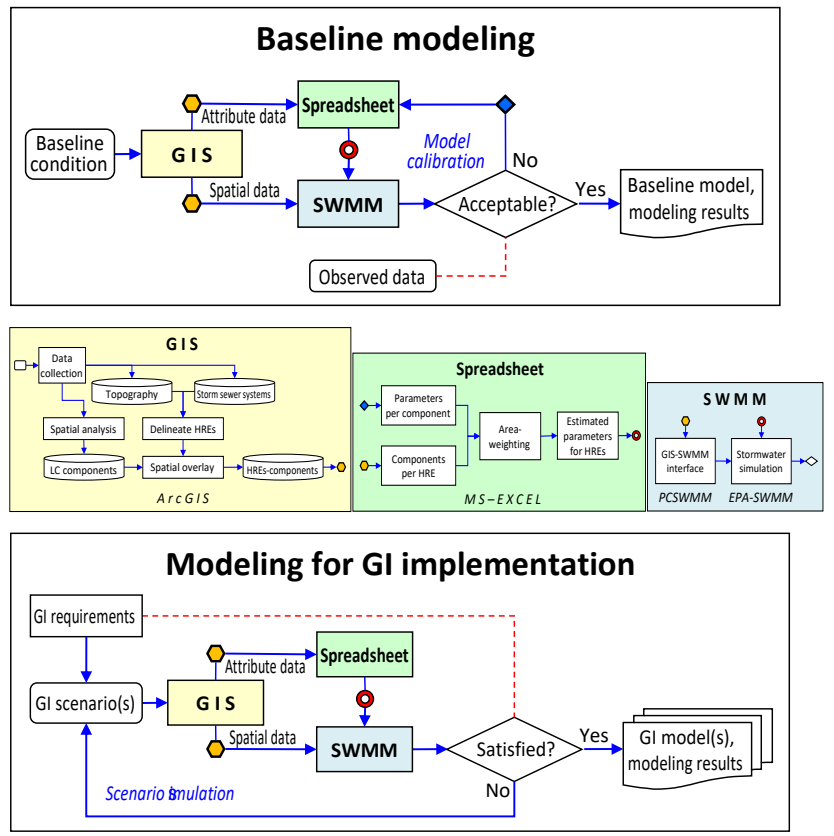

Figure A1. Procedures for SWMM modeling for GI analysis. LC stands for land cover. Conceptual workflow for each of the colored boxes is given in the middle of the diagram. Symbols $(\bullet \odot \diamond \square \diamond)$ are used to label workflow connections within the colored boxes. Top panel depicts the general steps used for baseline model setup, while the bottom panel adds GI considerations. "Acceptable?" indicates whether the statistical significance between the modeled and the observed hydrographs (e.g., Nash-Sutcliffe coefficient or $R^{2}$ ) is acceptable. "Satisfied?" indicates whether the modeling results are satisfied with the GI requirements.

width was set to $18.3 \mathrm{~m}$ (60 feet), was equal across all subcatchments, and was based on the average linear footage of BPA around the existing ICIA from distance measurements made using the GIS on a number of common ICIA features in the watershed, e.g., driveways, sidewalks, and miscellaneous outbuildings. Individual BPAs within a subcatchment are assumed to be parallelly aggregated in setting up the vegetated swale. The initial saturation was also equal across all subcatchments - set at $25 \%$ (this value self-equilibrates after the model warm-up period, see Sect. 2.6). The berm height of the vegetated swale was set at $2.54 \mathrm{~mm}(0.1 \mathrm{inch})$ to minimize any storage effect within the berm, which is the case for real BPA, and vegetation volume fraction was set to be 0 . The percentage of subcatchment imperviousness contributing to the BPA (i.e., the ICIA) is obtained by dividing the ICIA by the total IA. Since the total pervious area remains identical for each HRE, the sizes of SPA for individual HREs can be determined as SPA $=$ TPA - BPA for the three different sizes of BPA, which were derived by applying three different distances for the proximity analysis in GIS. When we calibrated the model, we checked which one, among the three cases of
BPA sizes established above, would calibrate the best for various storm sizes.

\section{A3 The groundwater component}

In SWMM groundwater flow is estimated by the following equation (Rossman, 2015):

$$
\begin{aligned}
Q_{\mathrm{gw}} & =A_{1}\left(H_{\mathrm{gw}}-H^{*}\right)^{B_{1}}-A_{2}\left(H_{\mathrm{sw}}-H^{*}\right)^{B_{2}} \\
& +A_{3} H_{\mathrm{gw}} H_{\mathrm{sw}},
\end{aligned}
$$

where $Q_{\mathrm{gw}}$ is the groundwater flow rate $\left[\mathrm{L}^{3} \mathrm{~T}^{-1}\right] ; H_{\mathrm{gw}}$ is the height of saturated zone above the bottom of aquifer [L]; $H_{\mathrm{sw}}$ is the height of surface water above the bottom of the aquifer [L]; $H^{*}$ is the threshold groundwater height [L]; and $A_{1}, A_{2}$, $A_{3}, B_{1}$, and $B_{2}$ is the empirically derived coefficients.

The top of the saturated zone is placed somewhere between the soil surface and the bottom of the aquifer. The $H^{*}$ is identical to the height of the streambed above the bottom of the aquifer (Rossman, 2015). No measurement data were available for relative elevations of the saturated zone or the bottom of the aquifer for the study area, but even with these values the groundwater parameterization in SWMM cannot be explicitly configured given the five coefficients that need specification (Eq. A3). Therefore, as is typical, we based the groundwater simulation on the elevation difference between individual subcatchment surface and its nearest stream bottom, which affects $H_{\mathrm{gw}}$. Groundwater modeling parameters were defined using the SWMM Reference Manual (Rossman and Huber, 2016) and SWMM users' group knowledge base (e.g., https://www.openswmm.org/Topic/ 1465/groundwater-parameters; https://www.openswmm.org/ Topic/4840/groundwater-values, last access: 20 April 2018). As part of simulating soil moisture content, evaporation is modeled by localized average daily rates for individual months obtained from an existing report (NOAA, 1982). The rates were taken directly based on the location of the study site without adjustment. 
List of abbreviations

\begin{tabular}{|c|c|}
\hline$A_{1}, A_{2}$, and $A_{3}$ & Empirically derived coefficients \\
\hline ASCE & American Society of Civil Engineers \\
\hline$B_{1}$ and $B_{2}$ & Empirically derived coefficients \\
\hline Bldg & Building \\
\hline BPA & Buffering pervious area that receives and controls runoff from impervious area \\
\hline DCIA & Directly connected impervious area \\
\hline DS & Depression storage \\
\hline DS_imp & Depression storage for impervious area \\
\hline ESRI & Environmental Systems Research Institute \\
\hline GI & Green infrastructure \\
\hline GIS & Geographic Information System \\
\hline$H^{*}$ & Threshold groundwater height \\
\hline$H_{\mathrm{gw}}$ & Height of saturated zone above the bottom of aquifer \\
\hline$H_{\mathrm{sw}}$ & Height of surface water above the bottom of the aquifer \\
\hline IA & Impervious area \\
\hline ICIA & Indirectly connected impervious area \\
\hline IMD & Initial (soil) moisture deficit \\
\hline$K_{\text {sat }}$ & Saturated hydraulic conductivity \\
\hline LID & Low-impact development \\
\hline Lidar & Light detection and ranging \\
\hline MR & Modeling result \\
\hline$\Delta \mathrm{MR}$ & Change in modeling result based on change in parameter value \\
\hline$n$ & Manning's roughness coefficient \\
\hline NOAA & National Oceanic and Atmospheric Administration \\
\hline NRC & National Research Council \\
\hline NRCS & Natural Resources Conservation Service \\
\hline NSE & Nash-Sutcliffe coefficient \\
\hline$p$ & Parameter value \\
\hline$\Delta p$ & Change in parameter value \\
\hline PA & Pervious area \\
\hline$Q_{\text {DCIA }}$ & Runoff from DCIA only \\
\hline$Q_{\mathrm{gw}}$ & Groundwater flow rate \\
\hline$Q_{\text {ICIA+BPA }}$ & Runoff from ICIA and BPA \\
\hline$Q_{\text {imperv }}$ & Runoff from impervious area (DCIA and ICIA through BPA) \\
\hline$Q_{\text {subsurface }}$ & Runoff through groundwater flow (i.e., subsurface or lateral flow) \\
\hline$Q_{\mathrm{SPA}}$ & Runoff from SPA only \\
\hline$Q_{\text {surface }}$ & Surface runoff without groundwater flow \\
\hline$Q_{\text {total }}$ & Total runoff with groundwater flow in SWMM \\
\hline$R^{2}$ & Coefficient of determination \\
\hline $\mathrm{SHC}$ & Shayler Crossing watershed \\
\hline Suct & Capillary suction head \\
\hline SPA & Standalone pervious area that does not receive or control any impervious area runoff \\
\hline SWMM & Storm Water Management Model \\
\hline TPA & Total pervious area \\
\hline TIA & Total impervious area \\
\hline Trpt & Transport \\
\hline USDA & United States Department of Agriculture \\
\hline USEPA & United States Environmental Protection Agency \\
\hline WEF & Water Environment Federation \\
\hline
\end{tabular}


Acknowledgements. The authors would like to thank Bill Mellman of Clermont County; Paul Weaver of APTIM; and Michael Tryby, Michael Elovitz, and William Shuster of the USEPA. They provided critical data, suggestions, and critical reviews.

Edited by: Louise Slater

Reviewed by: three anonymous referees

\section{References}

Braden, J. B. and Johnston, D. M.: Downstream economic benefits from storm-water management, J. Water Res. Pl., 130, 498-505, 2004.

Debo, T. N. and Reese, A. J.: Municipal Stormwater Management. 2nd Edition. Lewis Publishers, CRC Press, ISBN 9781566705844, 2002.

Dietz, M. E.: Low impact development practices: A review of current research and recommendations for future directions, Water Air Soil Poll., 186, 351-363, https://doi.org/10.1007/s11270007-9484-z, 2007.

ESRI: ArcGIS Desktop: Release 10.2., Environmental Systems Research Institute (ESRI), Redlands, CA, USA, 2013.

Fletcher, T. D., Andrieu, H., and Hamel, P.: Understanding, management and modelling of urban hydrology and its consequences for receiving waters - A state of the art, Adv. Water Res., 51, 261-279, 2013.

Gironás, J., Roesner, L. A., and Davis, J.: Storm Water Management Model Applications Manual, EPA/600/R-09/077, National Risk Management Research Laboratory, Office of Research and Development, U.S. Environmental Protection Agency (USEPA), Cincinnati, OH, USA, 2009.

Gregory, J. H., Dukes, M. D., Jones, P. H., and Miller, G. L.: Effect of urban soil compaction on infiltration rate, J. Soil Water Conserv., 61, 117-124, 2006.

Guo, J. C.: Volume-based imperviousness for storm water designs, J. Irrig. Drain. E., 134, 193-196, 2008.

Guo, J. C. and Urbonas, B.: Maximized detention volume determined by runoff capture ratio, J. Water Res. Pl.-ASCE, 122, 3339, 1996.

Homer, C. G., Dewitz, J. A., Yang, L., Jin, S., Danielson, P., Xian, G., Coulston, J., Herold, N. D., Wickham, J. D., and Megown, K.: Completion of the 2011 National Land Cover Database for the conterminous United States-Representing a decade of land cover change information, Photogramm. Eng. Rem. S., 81, 345354, 2015.

Horton, R., Ankeny, M. D., and Allmaras, R. R.: Effects of compaction on soil hydraulic properties, in: Soil Compaction in Crop Production, Elsevier Science B.V., Amsterdam, Netherlands, 479-500, 1994.

Huber, W. C.: New options for overland flow routing in SWMM, in: Urban Drainage Modeling, edited by: Brashear, R. W. and Maksimovic, C., Proc. of the Specialty Symposium of the World Water and Environmental Resources Conference, ASCE, Environmental and Water Resources Institute, Orlando, FL, 22-29, 2001.

Huber, W. C. and Dickinson, R.: Storm Water Management Model User's Manual, Version 4. EPA/600/3-88/001a (NTIS PB88236641/AS), Environmental Research Laboratory, Office of Re- search and Development, U.S. Environmental Protection Agency (USEPA), Athens, GA, USA, 1988.

Huber, W. C. and Cannon, L.: Modeling non-directly connected impervious areas in dense neighborhoods, in: Global Solutions for Urban Drainage, Proc. Ninth International Conference on Urban Drainage, edited by: Strecker, E. W. and Huber, W.C., Portland, OR. American Society of Civil Engineers, Reston, VA, CDROM, 2002.

Huff, F. A. and Angel, J. R.: Rainfall Frequency Atlas of the Midwest. National Weather Service, National Oceanic and Atmospheric Administration and Illinois State Water Survey, A Division of the Illinois Department of Energy and Natural Resources, Bulletin 71 (MCC Research Report 92-03) available at: http://www.sws.uiuc.edu/pubdoc/B/ISWSB-71.pdf (last access: 14 February 2015), 1992.

Krebs, G., Kokkonen, T., Valtanen, M., Setälä, H., and Koivusalo, H.: Spatial resolution considerations for urban hydrological modelling, J. Hydrol., 512, 482-497, 2014.

Lee, J. G., Heaney, J. P., and Lai, F. H.: Optimization of integrated urban wet-weather control strategies, J. Water Res. Plan. Man., 131, 307-315, 2005.

Lee, J. G., Nietch, C. T., and Panguluri, P.: SWMM Modeling Methods for Simulating Green Infrastructure at a Suburban Headwatershed - User's Guide, EPA/600/R-17/414, Water Systems Division, Office of Research and Development, U.S. Environmental Protection Agency. Cincinnati, OH 45268, available at: https://nepis.epa.gov/Exe/ZyPDF.cgi/P100TJ39.PDF? Dockey=P100TJ39.PDF, (last access: 15 February 2018), 2017.

Montalto, F., Behr, C., Alfredo, K., Wolf, M., Arye, M., and Walsh, M.: Rapid assessment of the cost-effectiveness of low impact development for CSO control, Landscape Urban Plan., 82, 117131, https://doi.org/10.1016/j.landurbplan.2007.02.004, 2007.

Niazi, M., Nietch, C., Maghrebi, M., Jackson, N., Bennett, B. R., Tryby, M., and Massoudieh, A.: Storm Water Management Model (SWMM) - Performance review and gap analysis, J. Sustain. Water B. Environ., 3, https://doi.org/10.1061/JSWBAY.0000817, 2017.

NOAA: Mean Monthly, Seasonal, and Annual Pan Evaporation for the United States. NOAA Technical Report NWS 34. U.S. Dept. of Commerce, National Oceanic and Atmospheric Administration, National Weather Service. Washington, D.C. December 1982, available at: http://www.nws.noaa.gov/oh/hdsc/PMP_ related_studies/TR34.pdf (last access: 15 February 2015), 1982.

NRC: Urban Stormwater Management in the United States. Committee on Reducing Stormwater Discharge Contributions to Water Pollution. National Research Council (NRC). National Academies Press., Washington, DC, ISBN: 978-0-309-12539-0, 2009.

Pitt, R.: Small storm hydrology and why it is important for the design of stormwater control practices, Adv. Mod. Manag. Stormw., 7, 61-91, 1999.

Rossman, L. A.: Storm Water Management Model User's Manual, Version 5.1, EPA/600/R-14/413b, Revised September 2015, U.S. Environmental Protection Agency, Office of Research and Development, Water Supply and Water Resources Division, Cincinnati, OH, USA, 2015.

Rossman, L. A. and Huber, W. C.: Storm Water Management Model Reference Manual, Volume I - Hydrology (Revised). EPA/600/R-15/162A, Revised January 2016, U.S. Environmen- 
tal Protection Agency, Office of Research and Development, Water Supply and Water Resources Division, Cincinnati, OH, USA, 2016.

Sample, D. J., Heaney, J. P., Wright, L. T., Fan, C. Y., Lai, F. H., and Field, R.: Costs of best management practices and associated land for urban stormwater control, J. Water Res. Plan. Man., 129, 59-68, 2003.

Sun, N., Hall, M., Hong, B., and Zhang, L.: Impact of SWMM catchment discretization: case study in Syracuse, New York, J. Hydrol. Eng., 19, 223-234, https://doi.org/10.1061/(ASCE)HE.1943-5584.0000777, 2014.

USDA: Urban Hydrology for Small Watersheds. Technical Release 55 (TR-55). Natural Resources Conservation Service, Conservation Engineering Division, U.S. Department of Agriculture (USDA), 1986.

USEPA: Reducing Stormwater Costs through Low Impact Development (LID) Strategies and Practices, EPA 841-F-07-006, Nonpoint Source Control Branch (4503T), U.S. Environmental Protection Agency, Washington, DC, 20460, 2007.

USEPA: Technical Guidance on Implementing the Stormwater Runoff Requirements for Federal Projects under Section 438 of the Energy Independence and Security Act. United States Environmental Protection Agency, Office of Water (4503T), Washington, DC 20460, EPA 841-B-09-001, December 2009, available at: http://www.epa.gov/oaintrnt/documents/epa_swm_ guidance.pdf (last access: 8 June 2015), 2009.
USEPA: Terminology of Low Impact Development - Distinguishing LID from other Techniques that Address Community Growth Issues, EPA-841-N-12-003, Office of Water, U.S. Environmental Protection Agency, Washington DC, 20460, 2012.

USEPA: What is Green Infrastructure? (Last updated on 13 June 2014) Office of Water, U.S. Environmental Protection Agency. Washington, DC 20460, available at: http://water.epa gov/infrastructure/greeninfrastructure/gi_what.cfm (last access: 8 May 2015), 2014.

WEF-ASCE: Design of Urban Stormwater Controls. WEF Manual of Practice (MOP) No. 23. ASCE Manuals and Reports on Engineering Practice No. 87, Water Environment Federation (WEF), Environmental \& Water Resources Institute, American Society of Civil Engineers (ASCE), ISBN-13: 978-0071704441, ISBN10: 0071704442, 2012.

Zhou, Q.: A review of sustainable urban drainage systems considering the climate change and urbanization impacts, Water, 6, 976992, https://doi.org/10.3390/w6040976, 2014. 